\title{
Risk-Based Versus Deterministic Explosives Safety Criteria
}

R. E. Wright

December 1996

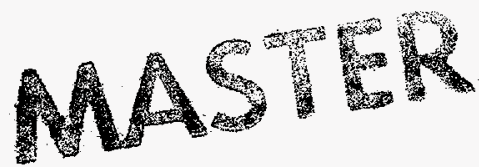

Prepared for the

U.S. Department of Defense under a Related Services Agreement with the U.S. Department of Energy under Contract DE-AC06-76RLO 1830

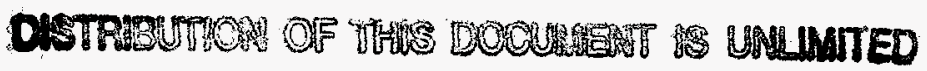

Pacific Northwest National Laboratory

Richland, Washington 99352 


\section{DISCLAIMIER}

Portions of this document may be illegible in electronic image products. Images are produced from the best available original document. 


\section{Acknowledgments}

The author would like to express his gratitude to Andreas Bienz and Peter Kummer of Bienz, Kummer and Partner, Ltd. for performing the risk calculations used as examples in this report, for their technical contributions and review comments, and for their historical information about the development of a riskbased approach to explosives safety.

Thanks are also extended to additional contributors of information to this report: Paul Price of the Headquarters Air Force Safety Center; Dr. Jerry Ward of the Department of Defense Explosives Safety Board (DDESB); Michael Swisdak, Jr. of the Naval Surface Warfare Center; Joseph Jenus, Jr. of AFMC/ ASC OL LIW(EHR); and Edward Jacobs and James Wassenberg of Integrated Systems Analysts, Inc. The author would also like to especially thank Dr. Canada of the DDESB for giving us the opportunity to conduct this study and for his support and guidance throughout the project. 


\section{Executive Summary}

The Department of Defense Explosives Safety Board (DDESB) is actively considering ways to apply risk-based approaches in its decision-making processes. As such, an understanding of the impact of converting to risk-based criteria is required. The objectives of this project are to examine the benefits and drawbacks of risk-based criteria and to define the impact of converting from deterministic to risk-based criteria. Conclusions will be couched in terms that allow meaningful comparisons of deterministic and risk-based approaches. To this end, direct comparisons of the consequences and impacts of both deterministic and risk-based criteria at selected military installations are made.

Deterministic criteria used in this report are those in DoD 6055.9-STD, "DoD Ammunition and Explosives Safety Standard." Risk-based criteria selected for comparison are those used by the government of Switzerland, "Technical Requirements for the Storage of Ammunition (TLM 75)." The risk-based criteria used in Switzerland were selected because they have been successfully applied for over twenty-five years.

\section{Advantages of the Risk-Based Approach}

The risk-based approach offers a number of advantages:

- A quantitative measure of risk can be determined and then compared to established and approved risk limits. The risk of directly involved personnel is also considered.

The risk-based approach allows a determination of a quantitative risk value (frequency of an occurrence multiplied by the resulting damage). This determination provides a means of measuring the risk of a given situation by comparing its risk value to approved safety criteria. These safety criteria can be derived from evaluating risks associated with similar work situations and determining acceptable levels of risk. Once determined, the risk of an explosives safety situation can be immediately evaluated against a standard. When noncompliances exist, decision makers can readily see the magnitude of the deviation from the Standard such as 6055.9. In part, DoD 6055.9 states: "when deviating from these standards, proper authority within the DoD components must weigh the added risk [emphasis added] to personnel and property against the strategic and other compelling reasons that necessitate such deviations." Since the quantity-distance approach does not provide a means to quantify risk, waivers or exemptions are sometimes authorized without a full awareness of risks involved.

The Q-D approach focuses on protecting non-involved exposed persons, whereas the risk-based approach considers risks for directly involved, indirectly involved personnel, and third parties. The premise of the risk-based approach is that no individual should bear a higher risk than any other person in the same situation. Often when protection for directly involved personnel is required, the Q-D approach, while demanding costly solutions for compliance, provides little difference in overall risk. 
- Noncompliances can be prioritized.

The risk-based approach provides an objective measure of risk and the amount the risk deviates from the acceptance criteria. As a result, different risk situations can be easily prioritized and resources to correct noncompliances can be properly allocated. In addition, the risk-based approach will identify areas where risk may be concentrated. Therefore, valuable resources can be targeted to achieve the most benefit. For example, in one actual situation, meeting the Q-D separation criterion would reduce the overall risk less than $1 \%$ because most of the risk is concentrated within the facilities, not between the facilities. Thus, money expended to obtain the separation required under the Q-D approach would have produced only a negligible reduction in risk. Also, under the Q-D approach, all noncompliances have the same importance, and there is no objective means for prioritizing different risk situations.

- Larger quantities of ammunition or shorter distances between potential explosives sites and an exposed sites can be established, which significantly reduces the number of waivers or exemptions, without reducing safety.

The risk-based approach is based on the concept that unwanted explosions and personnel exposures are probabilistic events. In contrast, the Q-D approach is deterministic in that an explosion and exposure to the explosion are considered certain events. The risk-based approach also considers energy absorption mechanisms and the probability of the full detonation of all explosives materials. Both of these factors contribute to reduction of the net equivalent weight of explosives. Because of these features, the riskbased approach permits larger quantities of ammunition or smaller distances than are permitted by the Q-D approach. These advantages produce an immediate impact on military readiness either because larger quantities of munitions will be permitted or because requests for waivers or exemptions will be greatly reduced. Such improvements are vitally important for military installations whose encroaching populations make compliance with the Q-D criteria difficult or impossible without affecting readiness.

- The introduction of an optimizing process into the risk appraisal process allows and compels decision makers to quantify when additional safety measures are needed and when they are not.

The fundamental reason for the safety criteria for individual risk is equity among the exposed persons. Thus, the responsible organization stipulates the safety criteria for the individual risk in terms of upper limiting values. In the practical case, the calculated individual risk is appraised by comparing it against these limits. If a calculated risk is higher than the limit, the situation is formally "unsafe" with respect to the individual risk, and measures have to be taken to reduce the risk under the limit.

The Swiss developed a process for the appraisal of the collective risk that could have exceptional economic benefit to the United States. In the case of the collective risk (the sum of the individual risks), the basic idea is to minimize the overall losses in the best possible way given that there are financial constraints, which in practice are always present. Thus, for the collective risk, upper limiting values alone are no longer reasonable criteria. Instead a measure called the "marginal cost" is used and is a ratio of cost permitted per saved life. Thus for a situation-determined collective risk, safety measures that can be used to reduce the collective risk must be evaluated in terms of the marginal cost. If the ratio of the cost of the 
safety measure to the collective risk does not exceed the marginal cost, the safety measure must be implemented. Conversely, if the marginal cost is exceeded, the safety measure does not have to be implemented and the situation is declared "safe."

For example, the collective risk of a situation was calculated to be $1.5 \times 10^{-3}$ fatalities/year. The expected loss over a fifteen-year period will be $2.25 \times 10^{-2}$ fatalities. If the marginal-cost is $\$ 20$ million for avoiding one fatality, the investment for the reduction of this risk must not cost more than $\$ 450,000$ $\left\{\$ 20 \mathrm{M}\left(2.25 \times 10^{-2}\right)\right\}$ within 15 years. If a measure exists that reduces the expected fatalities to a level of $8.5 \times 10^{-3}$ at a cost of $\$ 130,000$, then the original situation is formally "unsafe" (since $\$ 130,000 / 8.5 \times 10^{-3}$ is less than $\$ 20 \mathrm{M}$ ) and the new measure must be implemented. In contrast, another safety proposal that reduces the risk from $8.5 \times 10^{-3}$ to $7.3 \times 10^{-5}$ but costs $\$ 380,000$, must not be implemented, since it exceeds the marginal cost. In this case, the initial safety proposal with a remaining collective risk of $8.5 \times 10^{-3}$ in 15 years or $5.67 \times 10^{-4}$ fatalities/year is formally considered "safe" for collective risk.

This marginal-cost approach not only achieves safety for a reasonable price in the specific case, but also realizes the maximum of safety with the investment overall. The actual numbers of the marginal-cost criteria were laid down in Switzerland based on how much society, authorities, companies, groups or single persons are paying for safety within their field of responsibility and is thus called a "willingness-topay" approach.

\section{Field Implementation of the Risk-Based Approach}

A risk-based approach requires at least three elements: 1) a Standard such as DoD 6055.9-STD; 2) a risk-based computer code for risk-based analyses, and 3) trained personnel to conduct the analyses.

Probabilistic data need to develop a Standard can be acquired through one of three approaches:

- Acquire the data from sources now using a risk-based approach

- Acquire raw data based on experiences in the United States

- Combine the previous two approaches.

If used, information from sources now applying a risk-based approach must be reviewed to determine its applicability, and it must be approved for use in the United States. Computer codes, such as the Swiss program, RISKAMEXS, that perform risk-based analyses are available for purchase; however, it is recommended that a custom-designed computer code be developed for use by the U.S. military.

Although much of the needed information is also available in the United States, it must be collected, analyzed, documented, reviewed, and approved. If the information to implement a risk-based methodology is developed entirely in the United States, a first approximation of the cost would be $\$ 5.3$ million, and the total time required is estimated to be 38 months. 



\section{Contents}

Acknowledgments $\ldots \ldots \ldots \ldots \ldots \ldots \ldots \ldots \ldots \ldots \ldots \ldots \ldots \ldots \ldots \ldots \ldots \ldots \ldots \ldots \ldots \ldots \ldots \ldots$

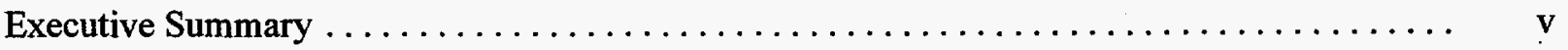

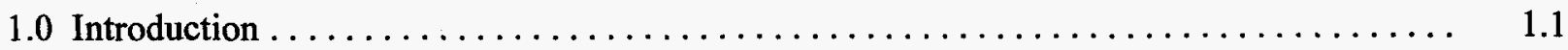

2.0 Main Elements of the Swiss Risk-Based Safety Concept $\ldots \ldots \ldots \ldots \ldots \ldots \ldots \ldots \ldots$

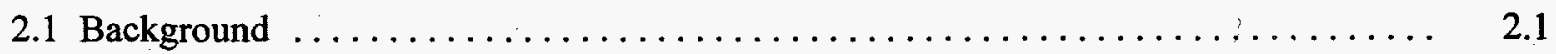

2.2 Differences in the Safety Perspective $\ldots \ldots \ldots \ldots \ldots \ldots \ldots \ldots \ldots \ldots \ldots \ldots \ldots \ldots \ldots \ldots \ldots$

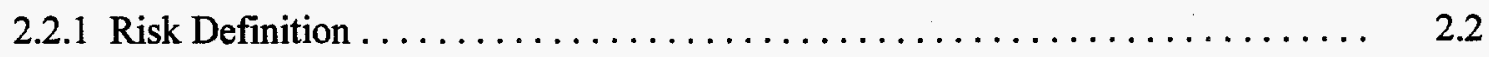

2.2.2 Element of a Risk-Based Study for Storage Applications $\ldots \ldots \ldots \ldots \ldots \ldots \quad 2.4$

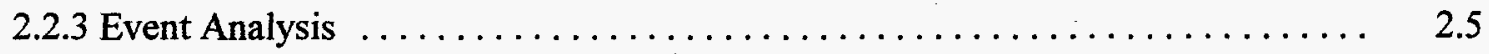

2.2.4 Effects Analysis $\ldots \ldots \ldots \ldots \ldots \ldots \ldots \ldots \ldots \ldots \ldots \ldots \ldots \ldots \ldots \ldots \ldots \ldots \ldots \ldots$

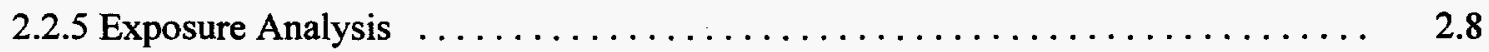

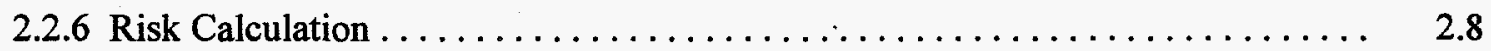

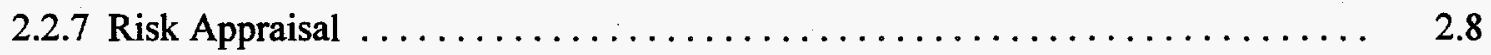

3.0 Comparison of the Risk-Based Method and the Quantity-Distance Method . . . . . . . 3.1

3.1 Overview of the Quantity-Distance Approach $\ldots \ldots \ldots \ldots \ldots \ldots \ldots \ldots \ldots \ldots \ldots$

3.2 Advantages and Disadvantages of the Two Approaches $\ldots \ldots \ldots \ldots \ldots \ldots \ldots \ldots$

4.0 Regulation, Organization and Management $\ldots \ldots \ldots \ldots \ldots \ldots \ldots \ldots \ldots \ldots \ldots \ldots \ldots \ldots \ldots$

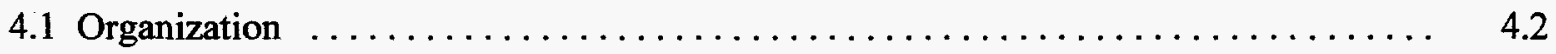

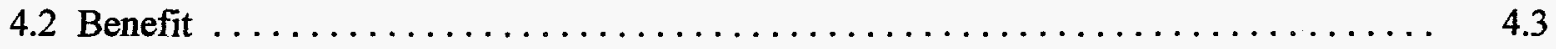

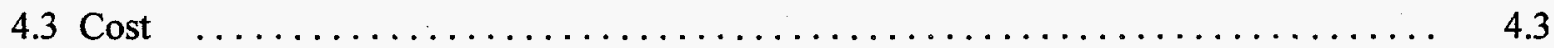

5.0 Management Considerations $\ldots \ldots \ldots \ldots \ldots \ldots \ldots \ldots \ldots \ldots \ldots \ldots \ldots \ldots \ldots \ldots \ldots \ldots \ldots \ldots \ldots \ldots$

5.1 Standard Development $\ldots \ldots \ldots \ldots \ldots \ldots \ldots \ldots \ldots \ldots \ldots \ldots \ldots \ldots \ldots \ldots \ldots \ldots \ldots \ldots \ldots \ldots \ldots \ldots$ 
5.1 .1 Safety Criteria $\ldots \ldots \ldots \ldots \ldots \ldots \ldots \ldots \ldots \ldots \ldots \ldots \ldots \ldots \ldots \ldots \ldots \ldots \ldots \ldots \ldots \ldots$

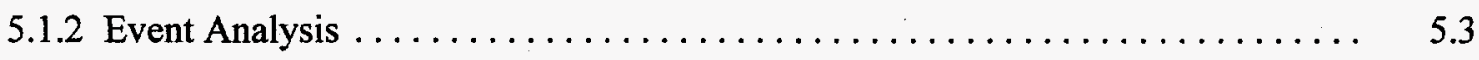

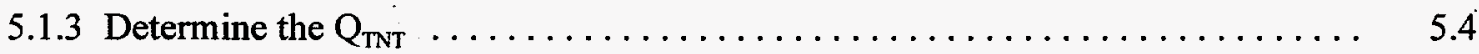

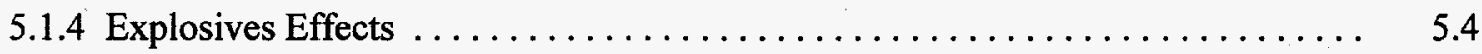

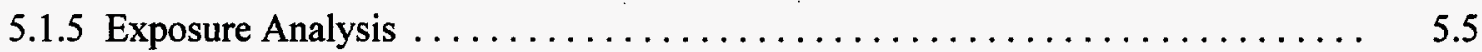

5.2 Computer Program for Risk Analysis and Appraisal $\ldots \ldots \ldots \ldots \ldots \ldots \ldots \ldots$

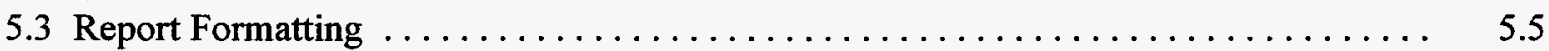

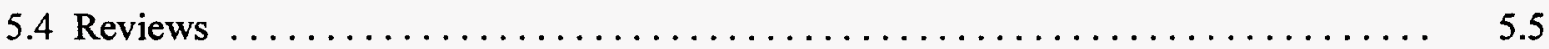

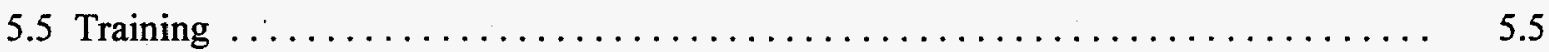

5.6 Field Use of a Risk-Based Program $\ldots \ldots \ldots \ldots \ldots \ldots \ldots \ldots \ldots \ldots \ldots \ldots \ldots \ldots \ldots \ldots \ldots \ldots$

5.7 Schedule and Cost for Implementation $\ldots \ldots \ldots \ldots \ldots \ldots \ldots \ldots \ldots \ldots \ldots \ldots \ldots \ldots \ldots \ldots \ldots \ldots$

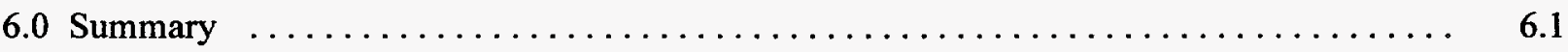

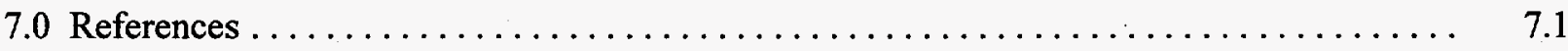

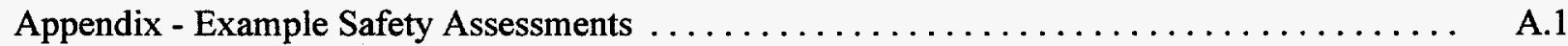




\section{Figures}

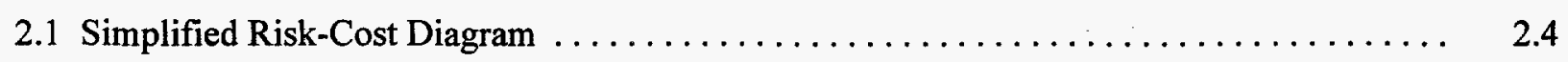

5.1 Timeline for Implementation $\ldots \ldots \ldots \ldots \ldots \ldots \ldots \ldots \ldots \ldots \ldots \ldots \ldots \ldots \ldots \ldots \ldots \ldots \ldots$

\section{Tables}

2.1 Average Annual Risk of Traumatic Occupational Fatalities $\ldots \ldots \ldots \ldots \ldots \ldots \ldots \ldots .2 .3$

2.2 Swiss Safety Criteria for Individual Risk $\ldots \ldots \ldots \ldots \ldots \ldots \ldots \ldots \ldots \ldots \ldots \ldots$

2.3 Swiss Marginal Cost Limits for Collective Risks $\ldots \ldots \ldots \ldots \ldots \ldots \ldots \ldots \ldots \ldots$

5.1 Swiss Safety Criteria for Individual Risk $\ldots \ldots \ldots \ldots \ldots \ldots \ldots \ldots \ldots \ldots \ldots \ldots \ldots \ldots$

5.2 Swiss Marginal Cost Limits for Collective Risks $\ldots \ldots \ldots \ldots \ldots \ldots \ldots \ldots \ldots \ldots \ldots \ldots \ldots \ldots$

5.3 Schedule and Cost to Implement the Risk-Based Approach $\ldots \ldots \ldots \ldots \ldots \ldots \ldots \ldots$ 


\subsection{Introduction}

For the past 70 years, the U.S. military has used a quantity-distance (Q-D) approach to explosives safety (DoD 1992). However, as population centers encroach on military installations, it is becoming increasingly difficult to satisfy the distance criteria of DoD 6055.90-STD. This situation causes additional requests for exemptions or waivers which have to be evaluated by personnel who do not have the benefit of a quantitative measure to determine the impact their decisions have on safety.

Through its participation in the "Klotz Club" and presentations at its DoD Explosives Safety Seminars, the Department of Defense Explosives Safety Board (DDESB) is aware that an alternative approach to explosives safety, called a risk-based approach, has been in use by military organizations in other countries. In particular, a quantitative risk-based approach developed by the Swiss Department of Defense has been in use by them for over 25 years in such areas as ammunition storage, fabrication and demilitarization (Swiss Army 1975). The risk-based approach permits a quantitative measure of risk as well as allowing economic considerations for proposed safety measures.

The DDESB desires an in-depth review of the risk-based approach to determine if it can be of use in solving the problem of population encroachment and the distance requirements imposed by DoD 6055.9 without sacrificing safety. The purpose of this report is to provide the DDESB with that analysis, including detailed examples demonstrating the methodology and its results. The Swiss firm Bienz, Kummer and Partner Ltd. was contracted by the DDESB as consultants to the Pacific Northwest National Laboratory ${ }^{(a)}$ for this evaluation. Bienz, Kummer and Partner Ltd. are long-term consultants of the Swiss Department of Defense and have had decisive influence on the development and introduction of the Swiss safety standard "WSUME" (main explosives safety directions) since its beginning over 25 years ago.

The approach used in this report is to describe the main elements of the Swiss risk-based safety concept; compare the risk-based and Q-D approaches; describe the Swiss regulations, organization and management considerations to implement a risk-based approach; and describe how the United States can implement a risk-based approach. In addition, two examples that fully describe the risk-based methodology and its results are provided in the appendix.

(a) Pacific Northwest National Laboratory is operated for the U.S. Department of Energy by Battelle under Contract DE-AC06-76RLO 1830. 


\subsection{Main Elements of the Swiss Risk-Based Safety Concept}

\subsection{Background (Bienz 1994)}

In the late $1940 \mathrm{~s}$, four catastrophic accidents in ammunition storage magazines occurred in Switzerland, killing 19 people and causing more than 100 million Swiss Francs of damage in the surroundings and to the storage installations. In addition, roughly 10,000 tons of ammunition were lost. The Swiss government established an Ammunition Storage Board uniting military and civilian logistic leaders and safety experts. After investigating of the accidents, one of the first tasks of this board was to work out new stringent safety regulations. In essence, these new regulations followed the traditional and widely accepted principles of safety distances to inhabited buildings and of various hazard categories for different types of ammunition. In addition, ammunition production processes were improved, less sensitive materials were used, and the quality of stored ammunition was continually controlled.

However, within a few years these regulations proved to be too inflexible to properly respond to new problems being created by the need to store steadily increasing amounts of increasingly explosive ammunition. Military readiness requirements called for additional storage space closer to the populated areas. At the same time, a greater number of residential, public and industrial buildings; recreational installations; and roads were built closer and closer to the existing storage installations. In addition, as with all organizations, the funds for safety improvements were limited.

The Ammunition Storage Board chose not to ignore the problem and continue to increase the number of waivers. It decided to investigate the problem thoroughly and realistically to work out new regulations that would provide the necessary help. The general direction was shown by the first experimental risk analyses performed in 1970 for two existing underground magazines. The capacity of these magazines was limited by the former safety regulation, not by space limitations. A risk vs quantity relationship was established for each individual magazine, taking into account the actual human activities in the surroundings. This relationship clearly showed which magazines could be filled beyond the limit given by the current regulation and which could not.

The Ammunition Storage Board founded a subcommittee consisting of military personnel, civilian officials and explosives experts and procured the necessary research funds. This organization, in essence, exists today.

The breadth of the safety problem was confronted by the subcommittee which addressed numerous and conflicting questions. There were military requirements such as readiness and protection against enemy weapon effects, cost, and safety aspects. It was desirable to maximize all three aspects at the same time, but this could not achieved by setting absolute requirements. Therefore, weighting factors were applied until an optimal solution was achieved. Concerning safety, it was felt that the best available approach was the quantitative risk concept and risk/cost-criteria. 
Several methodological, technical and political questions arose such as risk calculation procedures or data on dispersion of hazardous effects, effects on human beings, probabilities of explosion event, representative explosives quantities etc., or safety criteria. Many technical data were obtained from available literature. Other data were gained by modeling or testing. The safety criteria were discussed thoroughly and issued by the responsible authorities.

The basic work on methodology, data and the conceptual decisions was successfully applied to the establishment of new magazines. In addition, the methodology was applied to analyze explosives handling in a new assembly plant in one of the ammunition factories of the Defense Department. This activity lacked adequate regulations and criteria which would not have allowed safe and economical installations and operations. A study group was founded in the middle 1970s which developed the methodology for the safety assessment in ammunition factories. A risk analysis of all the working places of one of the factories underlined the feasibility of the quantitative approach also in this field of activities. The findings of this study were applied to the assembly plant project. Technical data for construction and risk analysis not currently available were gained via model tests. Several years later, the concept study was adapted to technical regulations, and the safety criteria were coupled with those of the storage activity.

\subsection{Differences in the Safety Perspective}

The Swiss approach identified safety from the perspective of the threatened individual, personnel responsible for the hazardous activity, and society.

The threatened individual focuses primarily on his own hazard and judges his risk based upon his own standard, regardless of how many other people are endangered. The organizations responsible for the hazardous activity are interested in limiting hazards in such a way that public opinion does not question the activity. Catastrophic accidents are much more of a concern to the public than smaller, but more frequent accidents. Society is interested in the total extent of the hazard as it would appear in accident statistics.

The Swiss safety assessment is composed of two parts: a risk analysis and a risk appraisal. The risk analysis deals with the objective analysis of the safety problem and the risk appraisal deals with the subjective aspect of social values.

\subsubsection{Risk Definition}

The most important part of this explosives safety approach is the definition of risk. The general use of the term "risk" is not precise and can be used to mean many different things. However, as used in a risk-based approach to explosives safety the term is defined precisely as the product of a frequency (or likelihood) of an event multiplied by the damage (or consequences) from the event:

$$
\mathrm{R}=\mathrm{F} * \mathrm{D}
$$

where $\mathrm{R}$ is risk, $\mathrm{F}$ is frequency and $\mathrm{D}$ is damage. 
For example, if three accidents occurred in an explosives factory in the last 100 years during a certain operation, each of them having fatally injured two operators,

- the average frequency of that accident would be $3 \times 10^{-2} /$ year

- the damage per accident would be 2 victims

- the individual risk of an operator at this operation would be $3 \times 10^{-2} /$ year $\times 1=3 \times 10^{-2} /$ year

- the collective risk of this operation would be $3 \times 10^{-2} /$ year $\times 2$ victims $=6 \times 10^{-2}$ victims/year.

A risk value takes on meaning when it is compared with the risk of more well-known events as shown in Table 2.1.

Table 2.1. Average Annual Risk of Traumatic Occupational Fatalities (CDC 1993)

\begin{tabular}{|l|c|}
\hline \multicolumn{1}{|c|}{ Activity } & Annual Risk \\
\hline Motor Vehicle & $1.61 \times 10^{-5}$ \\
\hline Machine & $9.5 \times 10^{-6}$ \\
\hline Homicide & $8.5 \times 10^{-6}$ \\
\hline Fall & $6.7 \times 10^{-6}$ \\
\hline Electrocution & $5.0 \times 10^{-6}$ \\
\hline Suicide & $2.2 \times 10^{-6}$ \\
\hline Fire & $1.3 \times 10^{-6}$ \\
\hline Drowning & $1.0 \times 10^{-6}$ \\
\hline
\end{tabular}

The Swiss methodology also differentiates between the relationship of the exposed person to the hazardous activity and the extent to which the person is able to influence his risk. In general, the differentiation is with directly involved individuals, indirectly involved individuals, and uninvolved third persons. Because of variations in the degree to which people in each of these categories can influence the risk or the benefits of accepting such risk, different risk limits are assigned to each category.

The main aspect under which the individual risk has to be appraised is equity: Nobody should bear a higher risk than any other person in the same situation. So the adequate safety criteria for the individual risk are upper limiting values. However, for collective risk, a marginal-cost-criterion is utilized instead of an upper limiting value. The concept is based on how much society is willing to pay for the safety of its members. Of course, there will not be consensus on the value of a human life. There are, however, numerous examples of the amount society is willing to pay for safety because, in practice, funds for such measures are finite. The marginal cost criterion is an exercise in optimization. The investment for safety is related to the achieved risk reduction (see Figure 2.1). One must continue pursuing risk reduction measures as long as the ratio of the cost to level-of-risk obtained does not exceed an established limit. 


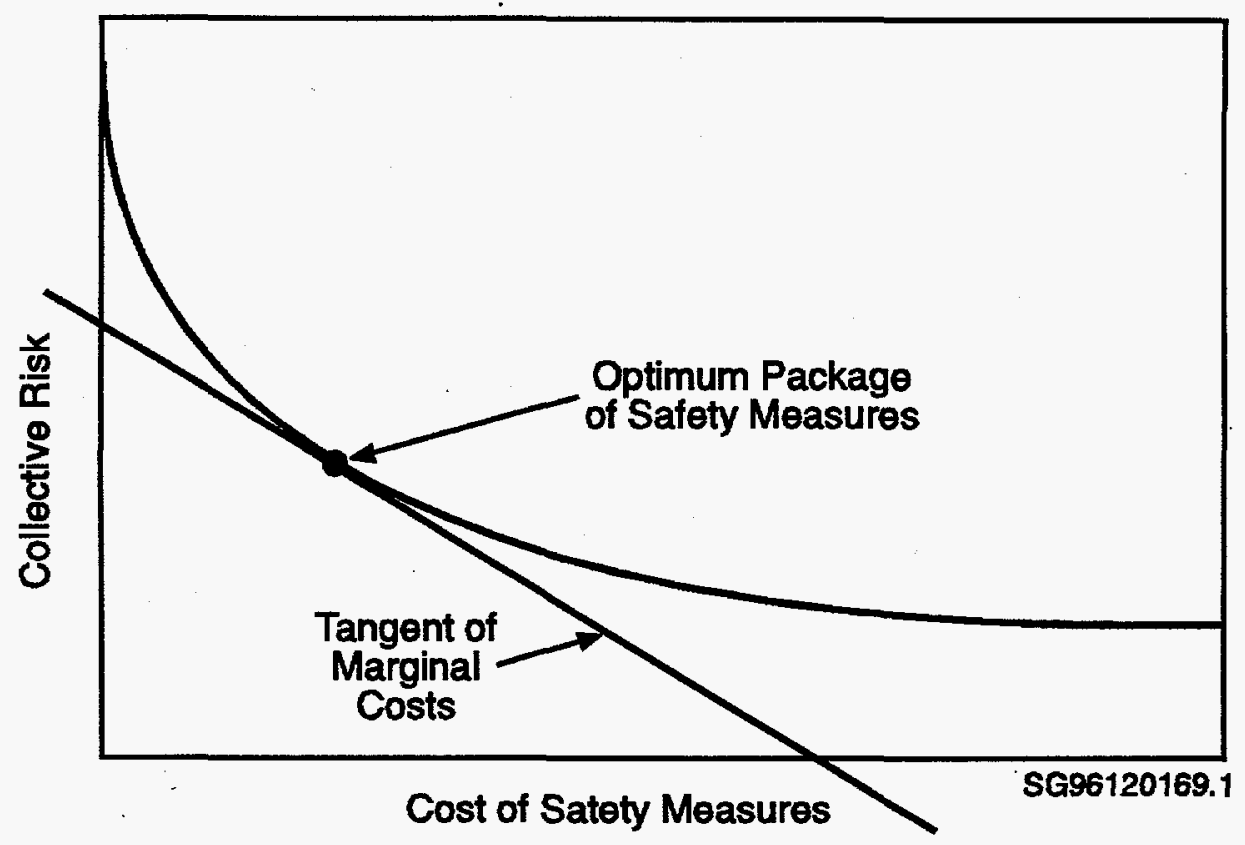

Figure 2.1. Simplified Risk/Cost Diagram

\subsubsection{Element of a Risk-Based Study for Storage Applications}

A risk-based study consists of a risk analysis and a risk appraisal (Bienz and Kummer 1992). The risk analysis consists of the following:

- Event Analysis - which identifies and describes the likelihood that an explosion will occur for the particular site and the quantity of explosives. ${ }^{(a)}$

(a) A feature of the Swiss approach is to quantify the amount of explosives engaged in the course of an explosion event in terms of the decisive or representative quantity of TNT which is abbreviated $\mathrm{Q}_{\mathrm{TNT}}$. According to the Q-D approach, the size of the explosion in a concentration of ammunition, which is the basic value for determining the safety distances, is defined as the total of the explosives (highexplosives, propellants, pyrotechnics, etc.) in the ammunition and is called the Net Explosives Weight (NEW) or Net Explosives Quantity (NEQ). The $\mathrm{Q}_{\mathrm{TNT}}$ model, however, considers 1) the energy of the different explosives which is different from that of the TNT value by the TNT equivalent, 2) the reduction effect on the airblast by the energy used by the fragmentation of the casing around the explosive and the acceleration of the fragments in terms of the casing factor, 3) the degree of participation of the single item in the course of explosion within the whole ammunition pile in terms of the participation factor. The $\mathrm{Q}_{\mathrm{TNT}}$ is different for different ammunition types, storage conditions (e.g., free stack or underground), reaction types (mass-detonation, non-mass detonation), etc. All these factors were determined for each type of ammunition stored in Switzerland. The actual values were and are derived from propagation tests, literature studies, and tests on casing behavior and TNT equivalents. In the end, more ammunition can be stored or handled with the $\mathrm{Q}_{\mathrm{TNT}}$ approach than with the NEW or NEQ model alone. 
- Effect Analysis - Determines the magnitude of the various hazards such as debris density, pressure, thermal, and the potential of death (lethality) from the various explosives effects. For example, given an explosion and a particular location that a person would occupy, the probability of death from a given debris density would be determined. The effects typically considered for detonations are fragment density, debris from structures and craters, and air blast.

- Exposure Analysis - Determines the probability that a person occupies a certain exposed location, given a specific type of explosion.

- Risk Calculation - Combines the information collected above to obtain the individual and collective risks and the perceived collective risk.

The risk appraisal consists of

- Comparing the obtained risk value for the particular situation with the approved individual upper limiting risk values.

- Evaluating safety measures to determine the cost/risk-reduction-value for comparison against the marginal cost criterion.

A more detailed description of each element of the risk analysis and risk appraisal is given below.

\subsubsection{Event Analysis}

The purpose of the event analysis is to determine the expected frequency of occurrence and the resulting yield of an explosion. An explosion and its yield are functions of numerous factors-the properties of the stored material, type of storage facility, type of construction, handling practices, and chemical compositions, to name a few.

For the case of storage of munitions, a linear relationship has been determined to calculate the initiating event frequency. Two classes of initiators are assumed in determining the frequency at which explosions are expected to occur. These are external initiators and internal initiators. External initiators include factors such as lightning; earthquakes; rock slides; forest fires; electric short circuits; and mechanical damage inflicted by humans, unintentionally or intentionally, during the storing process or during maintenance activities. Examples of internal initiators are chemical changes, fabrication errors, and mechanical effects such as collapsed shelving. An analytical expression that approximately models the statistical data collected for stored ammunition taking into account internal and external causes that have been developed. The linear model obtained is

$$
\mathrm{W}=\mathrm{A}+\mathrm{B}^{*} \mathrm{Q}
$$


where $\mathrm{W}=$ the average incidence frequency

$A=a$ constant that takes into account the type of construction of the facility, how well it is maintained, how secure it is from potential sabotage or external events

$\mathrm{B}=\mathrm{a}$ constant that takes into account the type of material stored, whether it is in good condition, and its behavior in regards to thermal propagation

$\mathrm{Q}=$ the gross amount of explosives material being stored.

The type of storage and type of construction are the main factors for determining the constant $\mathrm{A}$. The data taken into account are the susceptibility of the type of structure for damage from natural causes or human attack. Site-specific effects are usually neglected.

Factors that have the potential to affect the determination of the value of $\mathrm{A}$ are design; construction materials; current state of repair; type and current state of technical features; security features; antisabotage features; and increased site-specific risk from natural technical or human causes.

The term B has only two values: one for slow-reacting material in rock installations with special features, and the other for all other cases. If unusual arrangements for special materials have not been previously analyzed, then the constant B may need to be adjusted.

The propagation of an explosion must be considered if there is a possibility that the first explosion can trigger additional explosions in adjacent storage facilities. Propagation depends on such factors as the type and amount of affected material in the potential explosives site (PES), the geometry of the storage facilities, the distance between them, how they are connected, and the sensitivity of the material at the exposed site (ES). Therefore, simplifying assumptions are used.

The probability of propagation from one storage room to the next is calculated as follows:

$$
\mathrm{W}\left(\mathrm{L}_{1} \cap \mathrm{L}_{2}\right)=\left[\mathrm{W}\left(\mathrm{L}_{1}\right)\right] *\left[\mathrm{~W}\left(\mathrm{~L}_{2} \mid \mathrm{L}_{1}\right)\right]
$$

where $W\left(L_{1} \cap L_{2}\right)=$ probability of an explosion in storage room 1 and storage room 2

$\mathrm{W}\left(\mathrm{L}_{1}\right)=$ probability of occurrence for the initiating event in room 1

$\mathrm{W}\left(\mathrm{L}_{2} \mid \mathrm{L}_{1}\right)=$ conditional probability of propagation into room 2 , given an initiating event in room 1.

If all the requirements for propagation safety have been satisfied, the propagation probability will not need to be calculated. If not, propagation probabilities have to be analyzed. 


\subsubsection{Effects Analysis}

In the effects (consequence) analysis, the magnitude of the effects of any explosion are calculated by considering the debris density, both from the blast itself and from any buildings that may be damaged by the blast; the peak pressure; and the impulse pressure. Analytical expressions for calculating each of these values for a given distance from the explosion for various types of storage facilities have been determined.

The effects analysis determines the expected number of deaths (lethality) from an explosion. The calculation of lethality is based on the number of people in the exposure zone. Two approaches are possible, depending on the desired accuracy and the required effort to perform the calculations:

- The probability of death for each person in a given location is calculated; the sum of the individual deaths is the total number of deaths.

- Zones of constant lethality are defined by drawing lines of constant intensity around the event. The probability of death is calculated for each lethality zone. The sum of the number of deaths in each zone is the total number of deaths for the zone.

To determine the lethality zones, the intensities of the applicable effects from an explosion (debris ejection, shockwave, etc.) have to be known. Therefore, relationships between physical intensity and the resulting probability of death must be determined. The total lethality from a given location is calculated as the sum of the lethalities from the various physical effects.

The spatial intensity distribution of each explosives effect must be calculated and correlated with the probability of death. For example, the debris density will be a function of distance from the explosion. Given the debris density, the probability that an individual will be hit and killed can be determined. That probability will change, depending on whether the individual is in, for example, an open area, a forested area, or a building. A process similar to that used to determine the probability of death is performed for the other explosives effects such as pressure and pressure impulse.

The total lethality for a person exposed to $\mathrm{n}$ different effects from an explosion is generally calculated as

$$
\lambda=1-\left(1-\lambda_{1}\right)\left(1-\lambda_{2}\right) \ldots\left(1-\lambda_{n}\right)
$$

where $\lambda_{\mathrm{n}}=$ lethality values from the various effects at the given location

$\lambda=$ the total lethality.

The total lethality value can be determined for each exposed individual. However, this calculation is tedious and will normally be performed only with the use of a computer. Establishing lethality zones allows us to calculate lethality by hand. A lethality zone uses a constant lethality value. Five zones are established where the values used, in descending order, are $100 \%, 50 \%, 10 \%, 1 \%$ and $0.1 \%$. 


\subsubsection{Exposure Analysis}

The exposure analysis determines how many persons are likely to be present within a lethality zone of a postulated event. Suitable exposure parameters that permit individual or collective risk to be calculated are defined.

Within the lethality zones, specific objects are defined as a locality or a structure located within a lethality zone. Examples are streets, buildings, houses, playgrounds, etc. The number of people and their stay time inside a given object are determined. Daily, weekly, or seasonal patterns are taken into account. The population value within each object is determined. For example, the number of people occupying a road is the average number of people per car and the average number of vehicles per day or per hour. The total number of persons exposed to a lethal effect from the explosion multiplied by the probability of their exposure is the total consequence in terms of deaths per explosion.

\subsubsection{Risk Calculation}

In the risk analysis, the individual risk, collective risk and the perceived collective risks are determined. The individual risk calculation is simply the product of the initiating event frequency and the deaths per explosion, both of which have been calculated previously. The collective risk is the summation of the individual risks.

The perceived collective risk is the collective risk multiplied by an aversion factor, $\phi(\mathrm{A})$.

$$
\phi(\mathrm{A})=(0.2)^{2 \mathrm{~A}} \text { and } \phi(\mathrm{A}) \text { is } \leq 16
$$

where $A=$ the expected number of fatalities. The aversion factor takes into account the public's perception of the risk when larger numbers of people are killed in a single event. In general, the public will assign a higher risk value than is actual. Nonetheless, the perception becomes a real event that management personnel must deal with.

\subsubsection{Risk Appraisal}

Once the risk of the event is known, the risk appraisal can be performed. The risk appraisal is composed of two parts. In the first, the result obtained in the risk analysis is simply compared with the safety criteria. If the risk exceeds the safety criterion (shown in Table 2.2), then risk-reduction measures are required. If the required level of safety cannot be achieved, the activity is not permitted unless it is shown that exceptional need exists and increased risk levels are approved on a temporary basis. 
Table 2.2. Swiss Safety Criteria for Individual Risk

\begin{tabular}{|l|c|}
\hline \multicolumn{1}{|c|}{ Personnel } & $\begin{array}{c}\text { Maximum } \\
\text { Accepted } \\
\text { Individual } \\
\text { Risk/Year }\end{array}$ \\
\hline Directly involved persons & $1.0 \mathrm{E}-4$ \\
\hline Indirectly involved persons & $5.0 \mathrm{E}-5$ \\
\hline Non-participating third persons & $1.0 \mathrm{E}-5$ \\
\hline $\begin{array}{l}\text { Military personnel handling ammunition and } \\
\text { explosives }\end{array}$ & $3.0 \mathrm{E}-5$ \\
\hline $\begin{array}{l}\text { Military personnel dealing with ammunition } \\
\text { and explosives in exposure region of facility }\end{array}$ & $1.0 \mathrm{E}-5$ \\
\hline
\end{tabular}

The second part of the risk appraisal is called the marginal-cost approach, which establishes cost limits for safety measures to limit collective risks. These dollar limits for saving one life per year are roughly as shown in Table 2.3.

Table 2.3. Swiss Marginal Cost Limits for Collective Risks

\begin{tabular}{|l|c|}
\hline \multicolumn{1}{|c|}{ Personnel } & $\begin{array}{c}\text { Marginal Cost } \\
\text { for Avoiding } \\
\text { One Fatality }\end{array}$ \\
\hline Directly involved & $\$ 4$ million \\
\hline Indirectly involved & $\$ 8$ million \\
\hline Non-participating third persons & $\$ 20$ million \\
\hline $\begin{array}{l}\text { Military personnel handling } \\
\text { ammunition and explosives }\end{array}$ & $\$ 10$ million \\
\hline $\begin{array}{l}\text { Military personnel dealing with muni- } \\
\text { tions in exposure region of facility }\end{array}$ & $\$ 20$ million \\
\hline
\end{tabular}

In the case of the collective risk, the basic idea is to minimize the overall losses in the best possible way, given that there are financial constraints. Thus, for the collective risk, upper limiting values alone are no longer reasonable criteria. Instead a measure called the "marginal cost" is used and is a ratio of cost permitted per saved life. Thus for a situation-determined collective risk, safety measures that can be used 
to reduce the collective risk must be evaluated in terms of the marginal cost. If the ratio of the cost of the safety measure to the collective risk does not exceed the marginal cost, the safety measure must be implemented. Conversely, if the marginal cost is exceeded, the safety measure does not have to be implemented.

For example, the collective risk of a situation was calculated to be $1.5 \times 10^{-3}$ fatalities/year. In case the activity is planned to be in operation 15 years, the expected loss in this period will be $2.25 \times 10^{-2}$ fatalities. If the marginal cost is $\$ 20$ million for avoiding one fatality, the investment for the reduction of this risk must not cost more than $\$ 450,000\left\{\$ 20 \mathrm{M}\left(2.25 \times 10^{-2}\right)\right\}$ within 15 years. If there exists a measure which reduces the expected fatalities to a level of $8.5 \times 10^{-3}$ with an investment of $\$ 130,000$ for the period of 15 years, the original situation is formally "unsafe" (since $\$ 130,000 / 8.5 \times 10^{-3}$ is less than $\$ 20 \mathrm{M}$ ) and the measure has to be implemented. A different safety proposal that reduces the risk from $8.5 \times 10^{-3}$ to $7.3 \times 10^{-5}$ but costs an additional $\$ 380,000$ does not have to be implemented, however, because it exceeds the marginal cost. In this case, the initial safety proposal with a remaining collective risk of $8.5 \times 10^{-3}$ in 15 years or $5.67 \times 10^{-4}$ fatalities/year is formally considered "safe" with respect to the collective risk.

This marginal-cost approach not only achieves safety for a reasonable price in the specific case, but also realizes the maximum of safety with the investment overall. The actual numbers of the marginal-cost criterion were laid down in Switzerland based on how much society, authorities, companies, groups or single persons are paying for safety within their field of responsibility and is thus called a "willingness-topay" approach. 


\subsection{Comparison of the Risk-Based Method and the Quantity-Distance Method}

\subsection{Overview of the Quantity-Distance Approach}

The basic purpose of the quantity-distance requirement is to ensure an acceptable level of risk between a potential explosives site (PES) and an exposed site (ES). The required distance between a PES and an ES is determined by the hazard class/division of the explosives and the type of facility. Specifically, quantity-distance requirements are based on five factors (Eglin 1993):

- type of potential explosion site (facility design and function)

- explosives content (hazard class/division and the net explosives weight) of the potential explosives site

- type of exposed site (facility design and function)

- explosives content (hazard class/division and the net explosives weight) of the exposed site.

- distance separating the PES from the ES and the existence of barricades or natural terrain that provides additional protection.

If these quantities and distances are known, the distance that must separate the PES from the ES can be determined by the formula

$$
\mathrm{D}=\mathrm{K} * \mathrm{~W}^{1 / 3}
$$

where $\mathrm{D}$ is the distance in feet, $\mathrm{W}$ is the net equivalent weight of the explosives in pounds, and $\mathrm{K}$ is a safety multiplier applied to the cube root of the net explosives weight.

If the required distance between the PES and the ES cannot be obtained, corrective measures must be taken, e.g., reducing the amount of ammunition stored, meeting the required distance, or establishing barriers. If these measures cannot be implemented and a critical mission is jeopardized, a waiver or exemption must be requested.

\subsection{Advantages and Disadvantages of the Two Approaches}

The goal of either the risk-based method or the Q-D method is to achieve explosives safety. However, decisions for safety measures during explosives operations often compete with desires for military readiness, man-power utilization, and efficient use of available funding. When safety measures are considered, it is important to fully understand risk so that only effective measures are implemented and risk is reduced 
the maximum amount for the consumed resources. Only then can there be an optimization between increased safety and minimal impact on military readiness and available resources. It is in this area that the risk-based and the Q-D approach differ significantly.

The most significant aspect of the risk-based approach is that it provides a quantitative value for risk. Once risk is quantified, it can be used as an important tool in the explosives safety decision-making process, and absolute safety criteria can be established. The degree of any nonconformances can be immediately measured against the safety criteria, and multiple nonconformances can be ranked by importance. The Q-D approach cannot measure risk objectively, only subjectively. There is no distinction, whether a nonconformance is off by one foot or 500 feet. Each is treated with the same importance.

Another significant aspect of explosives safety is the proper identification of risk areas. For example, as shown in the example in the Appendix of this report, multiple facilities housing explosives are both potential explosives sites and exposed sites. The risk-based approach identifies the risk of the directly involved personnel and the indirectly involved personnel. As the example shows, almost the total risk is contained with the PES and not between it and the exposed sites. The Q-D approach does not identify the risk to the directly involved personnel at all. It is only used to establish the correct distance between a PES. and an ES. Should there be a nonconformance, valuable resources could be spent that would have almost no effect in reducing the actual risk.

The risk-based approach takes a realistic evaluation of an explosives safety situation and generally either permits closer spacing between PES and ES or increased amounts of explosives materials. In addition, fewer waivers and exemptions are required. This approach views unwanted explosions as probabilistic events, not certain ones, as is assumed in the Q-D approach. In addition, energy may be consumed in the fragmentation process; not all of the explosives detonate simultaneously; or some may not detonate at all. Finally, the risk-based approach examines the likelihood that an individual will be exposed even if an accident occurs. The Q-D approach assumes all individuals will be exposed during a blast. As a result, the risk-based approach is generally less conservative and has fewer demands on limited resources than does the Q-D approach.

Another benefit of the risk-based approach is that it deals with both the objective risk and the perceived risk. Often, in dealing with the public, management must deal with perceived risk. Management must often anticipate how an accident might be viewed by the general public before the accident happens. The actual collective risk is multiplied by a calculated aversion factor modeling the public's reaction to an accident. This approach is not possible with Q-D criteria.

Another extremely valuable management tool for the decision maker is the ability to establish maximum cost limits for reduction of collective risk. It is possible to objectively determine when no further safety measures are necessary based on established and approved cost/risk ratio limits. Using the same information, it is possible to determine the optimum safety improvements, that is, the largest reduction of risk for the least amount of funds. This benefit is very important because it allows limited funds to be maximized, possibly making unused funds available for other critical needs. 
The above-stated benefits of the risk-based approach, however, are not without drawbacks. The riskbased approach is much more analytical than the Q-D approach, adding a degree of complexity. Thus explosives safety personnel must receive additional training on how to perform the analyses and how to . correctly interpret the results. In addition, the risk-based approach acquires a much larger data base (and its associated development and maintenance cost), containing, for example, initiating event frequencies, population patterns for each facility, explosives effects, and lethality estimates. The analyses are carried out on a computer code which will have to be customed designed and maintained for U.S. military application. Initial development cost will be significant, but payback time should be short because the costbenefit implementation of safety measures is optimized.

Neither approach affords perfect safety. However, with the risk-based approach, the risk can be measured and kept below a level which is deemed acceptable. 


\subsection{Regulation, Organization and Management}

The purpose of this section is to describe some of the regulations, organizational, and management structure the Swiss government created to manage a risk-based approach to explosives safety.

The regulations begin with the Swiss Explosives Law. This law releases the military forces and the military administration from the substantive content of the law and decrees, but commits the government to issue its own concepts and regulations for this field. The government assigned this duty to the Defense Department, where the Chief of General Staff is responsible for the safety of the handling of ammunition and explosives by the forces and the administration.

The Chief of General Staff enacted the "Directives Concerning the Safety of the Handling of Ammunition and Explosives by the Military Forces and the Military Administration" (the German abbreviation is "WSUME"). These directives lay down the general safety goal (e.g., the protection of human life and absence of injury), the quantitative safety criteria, duties and responsibilities of the subordinate spheres, and the policy on information to the public.

The "TLM75" are the regulations for the ammunition and explosives storage in peace time, an activity several agencies of the Swiss Defense Department are concerned with. "TLM" is a German abbreviation for "Technical Regulations for the Storage of Ammunition." The 75 means that it was enacted in 1975. TLM 75 is composed of five parts:

\section{General Principles}

2. Safety Assessment

3. Planning and Construction of Magazines

4. Storing of Ammunition

5. Storing of Ammunition by the Troops

The safe handling of ammunition and explosives in ammunition and propellant factories is governed by the WAE. "WAE" is a German abbreviation for "Directives for the Safety in Federal Armament Factories with Explosives Hazards." It consists of two parts: "General Principles and Responsibilities" and "Guidelines to Perform Safety Assessments." 


\subsection{Organization}

Many different military and civilian agencies are involved with ammunition and explosives handling. Therefore coordination is necessary for economical management with a maximum safety benefit. For this purpose, several permanent bodies were founded.

The Ammunition Storage Board, now called the "Committee for the Safety of Handling with Ammunition and Explosives by Forces and Administration," consists of the Deputy Chief of Staff Logistics as Chairman, the Deputy Chief of Staff Instruction, and a Vice Director of the Defense Technology and Procurement Agency. This committee advises the Chief of General Staff concerning storage and ammunition and explosives safety. It leads and coordinates the management of the storage, the development and revision of regulations, and the basic research in this field. A Safety Deputy and a "Project Committee" serve as advisors. The Safety Deputy is the safety expert for the Committees and the Defense Department's risk manager for ammunition and explosives storage. The Project Committee comprises a dozen high-ranked members of all the military and civilian sections, as well as the leaders of the study groups who are concerned with ammunition and explosives procuring, fabrication, transport, and storage. Its responsibilities are to optimize safety in each of these areas. The Project Committee meets once or twice a year with the Committee for the Safety of Handling with Ammunition and Explosives by Forces and Administration.

The decisions are made and work is done by a number of study groups:

- The "Basics" study group works on long-term projects and is concerned with methodology, models, data, and criteria for safety assessment and risk management on several levels of ammunition and explosives handling. It consists of half a dozen experts from the administration, among them the Committee Safety Deputy and private consultant experts. As the oldest team, the Basics performed the first risk analysis more than twenty years ago.

- The five "TLM" study groups work on the regulations TLM75. Their four to eight members, who come from several agencies and from private consultants, are specialists or managers.

- Three management study groups are working to improve the overall concepts for storing the ammunition for the Army and the Air Force. These groups have about six members and leaders, who come from several agencies.

No special organization has been created for safety in fabrication of ammunition and explosives because it can be ensured by the existing organization. An expert team consists of the safety deputies of the factories who exchange know-how and experiences and take care of the regulations. In the field of transport, there is no special organization at the moment. It is possible that there will be a study group added to the organization described above. 


\subsection{Benefit}

Over the years, the organizational structure described above has provided three main advantages:

1. The methodological concept of quantitative safety assessment makes the hazards of ammunition and explosives handling comprehensible and intelligibly visible and comparable. The responsible people actually know the responsibilities they take.

2. The regulations can actually be applied. The number of waivers has decreased significantly compared with former times.

3. The necessary safety level can be achieved economically, e.g., so far the flexible assessment concept has allowed solutions that saved millions of Swiss francs.

\subsection{Cost}

It is estimated that implementation cost by non-governmental personnel was approximately $\$ 14$ million $(\$ 14,000,000)$. 


\subsection{Management Considerations}

Many factors-such as cost, time to implement such a program, and the number and type of personnel who would be required to administer-must be considered in any implementation of the risk-based approach. The activities necessary for implementation would consist of developing 1) a Standard, either a stand-alone document or a revision to the current $6055.9 ; 2$ ) a computer program to perform the risk analysis and appraisal calculations; and 3) a training program for explosives safety personnel.

Time and cost estimates to implement the system are discussed below. The time estimates are average values for nonmilitary personnel; the cost estimates are based on an average labor cost of $\$ 85$ per hour. Except for travel cost, the cost for military personnel participation is not included in these estimates.

The task of establishing a risk-based program would be accomplished most effectively by a Technical Working Group made up of explosives experts, risk analysts, statisticians, physicists, structural analysts, and medical personnel. We recommend that the DDESB establish such a working group.

\subsection{Standard Development}

The major components of the Standard to be developed are a set of risk-based safety criteria to set limits for individual risk; the marginal cost for collective risks; the information (data and procedures) for each of the four risk-based methodology steps (event analysis, effect analysis, exposure analysis, risk calculation); and the methodology for the risk appraisal. The Swiss Department of Defense has already developed all of this information for storage of ammunition, and much of it is available for direct use or as guidance. Because U.S. ammunition storage, handling, training, and safety measures may differ from the Swiss, however, the adequacy of this information for use in the United States must be evaluated.

\subsubsection{Safety Criteria}

The Swiss Department of Defense has developed safety criteria that would likely be representative of the values applicable to the United States. The Swiss safety criteria for individual risks are shown in Table 5.1.

These risk criteria represent the findings of studies performed to determine an acceptable level of risk for personnel who are performing or associated with similar hazardous work. These values are likely to be representative of the values applicable to situations within the United States. Because of their importance, however, their applicability to the United States must be confirmed.

For example, not all of the personnel categories shown in Table 5.1 are directly applicable. The Swiss include categories for military personnel because Switzerland does not have a standing army, and civilian personnel are more directly involved with day-to-day handling of ammunition than are military personnel. It may be that only the first three categories are applicable. Others that relate more directly to the situation in the United States may need to be added. 
Table 5.1. Swiss Safety Criteria for Individual Risk

\begin{tabular}{|l|c|}
\hline \multicolumn{1}{|c|}{ Personnel } & $\begin{array}{c}\text { Maximum } \\
\text { Accepted } \\
\text { Individual } \\
\text { Risk/Year }\end{array}$ \\
\hline Directly involved persons & $1.0 \mathrm{E}-4$ \\
\hline Indirectly involved persons & $5.0 \mathrm{E}-5$ \\
\hline Non-participating third persons & $1.0 \mathrm{E}-5$ \\
\hline $\begin{array}{l}\text { Military personnel handling ammunition and } \\
\text { explosives }\end{array}$ & $3.0 \mathrm{E}-5$ \\
\hline $\begin{array}{l}\text { Military personnel dealing with ammunition } \\
\text { and explosives in exposure region of facility }\end{array}$ & $1.0 \mathrm{E}-5$ \\
\hline
\end{tabular}

Information from which to obtain or derive applicable safety criteria is readily available. Organizations such as the Occupational Safety and Health Administration and the Centers for Disease Control, for instance, would likely have information on the probability of death from certain activities (e.g., working at or near chemical processing plants, high voltage electrical facilities, nuclear power plants, construction sites) whose associated risks are comparable to those of the explosives field.

Collecting the data, analyzing it, and documenting the results would require approximately four months for a staff of two statisticians and an explosives safety expert, who will help ensure that applicable occupational risk data are being collected.

The Swiss have also developed marginal costs (see Table 5.2) for safety measures to limit the collective risk. While these values could be used as a gauge, their applicability for use in the United States should be evaluated. The Swiss DoD had determined upper limits for perceived collective risks and had evaluated

Table 5.2. Swiss Marginal Cost Limits for Collective Risks

\begin{tabular}{|l|l|}
\hline \multicolumn{1}{|c|}{ Personnel } & \multicolumn{1}{|c|}{$\begin{array}{c}\text { Marginal Cost } \\
\text { for Avoiding } \\
\text { One Fatality }\end{array}$} \\
\hline Directly involved & $\$ 4$ million \\
\hline Indirectly involved & $\$ 8$ million \\
\hline Non-participating third persons & $\$ 20$ million \\
\hline $\begin{array}{l}\text { Military personnel handling } \\
\text { ammunition and explosives }\end{array}$ & $\$ 10$ million \\
\hline $\begin{array}{l}\text { Military personnel dealing with muni- } \\
\text { tions in exposure region of facility }\end{array}$ & $\$ 20$ million \\
\hline
\end{tabular}


the costs associated with a safety upgrade program for their munitions storage system. They also examined U.S. and French studies that addressed appropriate cost limits for specific hazardous activities. In addition, the Swiss examined the cost to other organizations for implementing safety measures such as traffic control systems and studies.

A similar study for U.S. situations is estimated to require six months of effort by an explosives safety expert and two risk analysts.

\subsubsection{Event Analysis}

The event analysis determines the frequency of the initiating event The frequency can be determined through one of three basic methods: empirical, analytical, or subjective. Where sufficient statistical data exist, estimating the probability is a straightforward empirical process. If sufficient information does not exist, analytical methods such as fault trees or the subjective estimates of experts using Bayesian statistical methods can be used. Fault tree analysis uses boolean algebra to logically reduce major events to subevents and to a level where statistical information is adequate for the task of assigning probability values. Subjective frequency determination is accomplished by statistically polling safety explosives experts on the likelihood of explosions.

The Swiss have developed linear relationships between the quantity of explosives and the probability of explosion for the storage of munitions. Although they are likely to be applicable to U.S. storage facilities, these equations should be verified for use in the United States. Frequencies for other initiating events will be conditional probabilities - for example, the probability of an explosion, given a particular explosives material or given a particular activity such as melting, pressing, handling, or storing.

Regardless of the method used to determine the initiating event frequency, five specific steps need to be completed:

- determine the data to be collected

- collect data

- analyze data

- develop mathematical model from the data

- document the four preceding steps.

An explosives safety expert working with a risk analyst can identify the range of activities for which explosives event frequencies are to be determined. Examples of activities to be considered are munition storing, handling, production, testing, and training. For each of these activities, further considerations such as the type of explosives applicable to that activity, as well as the environmental conditions such as extreme heat or cold, humidity, and violent weather conditions, should be included in the evaluation. 
Applicable mishap data are likely available from the DDESB, the Department of Energy, and other government agencies, as well as from foreign governments.

We estimate that an explosives safety expert, a risk analyst, and a statistician could perform the five steps over a 21 -month period.

\subsubsection{Determine the $Q_{\mathrm{TNT}}$}

The next step in the event analysis is to determine the $Q_{\mathrm{TNT}}$. The Swiss approach uses three factors: 1) TNT equivalent, 2) casing factor, and 3) participation factors. Determining the TNT equivalent for different quantities of ammunition is well known under the Q-D approach; however, use of the casing factor is not straightforward. Discussions with U.S. explosives safety experts indicate the existence of some controversy regarding use of the casing factor. Studies have indicated that some energy is returned to the blast wave as the casing cools, a phenomenon that would minimize the reduction from the TNT equivalent. In addition, explosives testing studies have shown that mass detonation of Hazard Division 1.1 explosives is not always the case, as there is some staggering of explosions. In addition, some ammunition is thrown from the event and does not react at all. The studies should be reviewed, and discussions with experts should be conducted to determine the applicability of the casing factor and the participation factor.

It is estimated that an explosives safety expert and an expert in the area of mechanical effects of munitions could obtain this information over a 6-month period.

\subsubsection{Explosives Effects}

The spatial blast effects must be known for each type of effect such as debris density, peak overpressure, thermal, and ground shockwave. Once the spatial effect is known, the probability of death from that effect must be determined. The lethality depends on many factors, such as the type of storage, the type of blast effect, whether personnel have buildings or vehicles in which they can take cover or whether they are standing in a free field. As a result, mathematical functions relating the probability of death for each type of storage facility and each type of blast effect will have to be determined. The process of determining lethality from the various blast effects is quite complex. In general, the information is available in the United States or in countries that would make the information available upon request. The information is not centrally located, however, and a considerable effort will be necessary to collect it and analyze the data.

Personnel with a medical science background would be necessary to review data relating blast intensities to lethality. In addition, since lethality can occur from secondary effects such as falling debris and collapsing buildings, personnel such as physicists and structural engineers will need to calculate the loading effects. An explosives expert would be required to coordinate the data collection. With four people assigned, the task is estimated to be completed in 24 months for explsoives effects. Two medical personnel and two risk analysts could determine the probability of lethality in 12 months. 


\subsubsection{Exposure Analysis}

Exposure analysis determines the probability that a person will actually be exposed to an explosion. Population exposure to a potential explosion is site-specific. Therefore, only the methodology to perform an exposure analysis need be documented in a Standard such as 6055.9. The process is well documented in the Swiss methodology. It could simply be adopted for use in the United States and put into a format that is consistent with the Standard. This task could be accomplished by two people working for approximately three months.

\subsection{Computer Program for Risk Analysis and Appraisal}

A computer program would be used to permit rapid data entry and calculation of risk analysis and risk appraisal. The program should be designed so that personnel who currently conduct $Q-D$ analyses can use it after minimal training. The program should also contain a current graphical interface system and should meet the verifications and validations for military computer programs. It is recommended that the program be integrated with a computer program, "Explosives Site Planning System," which the DDESB is currently evaluating for full military application. This program has been applied at several Air Force bases and is based on the Q-D approach.

Although computer programs are currently available for performing risk-based explosives safety analysis for munitions storage situations, they are not likely to meet the strict validation and verfication requirements of the military nor would they provide flexibility to meet its long-term needs. Therefore, we recommend that a custom program be developed. Prototype development of a computer program could be completed by four computer programmers over a period of 12 months with a full operational program available in 24 months.

\subsection{Report Formatting}

Combining all the above sections into a report for review by the applicable branches of the U.S. military and the DDESB and, subsequently, for inclusion into a Standard, such as 6055.9, can be accomplished by two people working approximately four months.

\subsection{Reviews}

After the report is formatted, it will need to be reviewed by each service's Senior Safety Council and by the DDESB. The estimate for these.reviews is two people per service, working for one month.

\subsection{Training}

All applicable military personnel must be trained on the use of the risk-based approach. For purposes of cost estimation, it is assumed that 100 military bases would implement the approach and that two people 
from each base would be trained. To permit hands-on training, each training session should be limited to approximately 20 people. This configuration would require 10 centrally located, two-week training sessions. One-time course preparation would require two people for one month.

\subsection{Field Use of a Risk-Based Program}

Field use of a risk-based program would likely be administered in the same manner as the Q-D approach is currently administered. The applicable personnel would be trained on the risk-based approach, the interpretation of the results, and the use of the computer program. Additional cost over that of the Q-D approach would include the cost to model initial population exposures at a base and necessary updates as situations change and as new munitions are placed into service. These costs are not estimated here.

\subsection{Schedule and Cost for Implementation}

Table 5.3 summarizes the estimated schedule and costs for implementing the risk-based approach. Figure 5.1 shows a first approximation of a timeline for the 24 months estimated for field implementation.

Table 5.3. Schedule and Cost to Implement the Risk-Based Approach

\begin{tabular}{|l|c|c|c|c|c|}
\hline \multicolumn{1}{|c|}{ Activity } & $\begin{array}{c}\text { No. of } \\
\text { FTE }\end{array}$ & $\begin{array}{c}\text { Staff } \\
\text { Months }\end{array}$ & $\begin{array}{c}\text { Calendar } \\
\text { Months }\end{array}$ & Cost & Travel \\
\hline Safety criteria & 3 & 12 & 4 & $\$ 180,000$ & $\$ 10,000$ \\
\hline Cost criteria & 3 & 18 & 6 & 265,000 & 10,000 \\
\hline Event analysis & & & & & 20,000 \\
$\quad$ Identify data & 3 & 15 & 5 & 220,000 & \\
$\quad \begin{array}{l}\text { Anallect data } \\
\text { Develop mathematical model } \\
\text { Document steps }\end{array}$ & 3 & 21 & 7 & 310,000 & \\
\hline QTNT & 3 & 9 & 3 & 130,000 & \\
\hline Explosives effects and & 2 & 12 & 6 & 130,000 & \\
Probability of lethality & 4 & 96 & 24 & $1,400,000$ & 20,000 \\
\hline Exposure analysis & 3 & 36 & 12 & 550,000 & 10,000 \\
\hline Computer code & 2 & 6 & 3 & 90,000 & 7,000 \\
\hline Standard format & 4 & 96 & 24 & $1,400,000$ & 20,000 \\
\hline Seminars/training (12) & 2 & 8 & 4 & 120,000 & \\
\hline Total & 2 & 12 & 6 & 175,000 & 160,000 \\
\hline
\end{tabular}




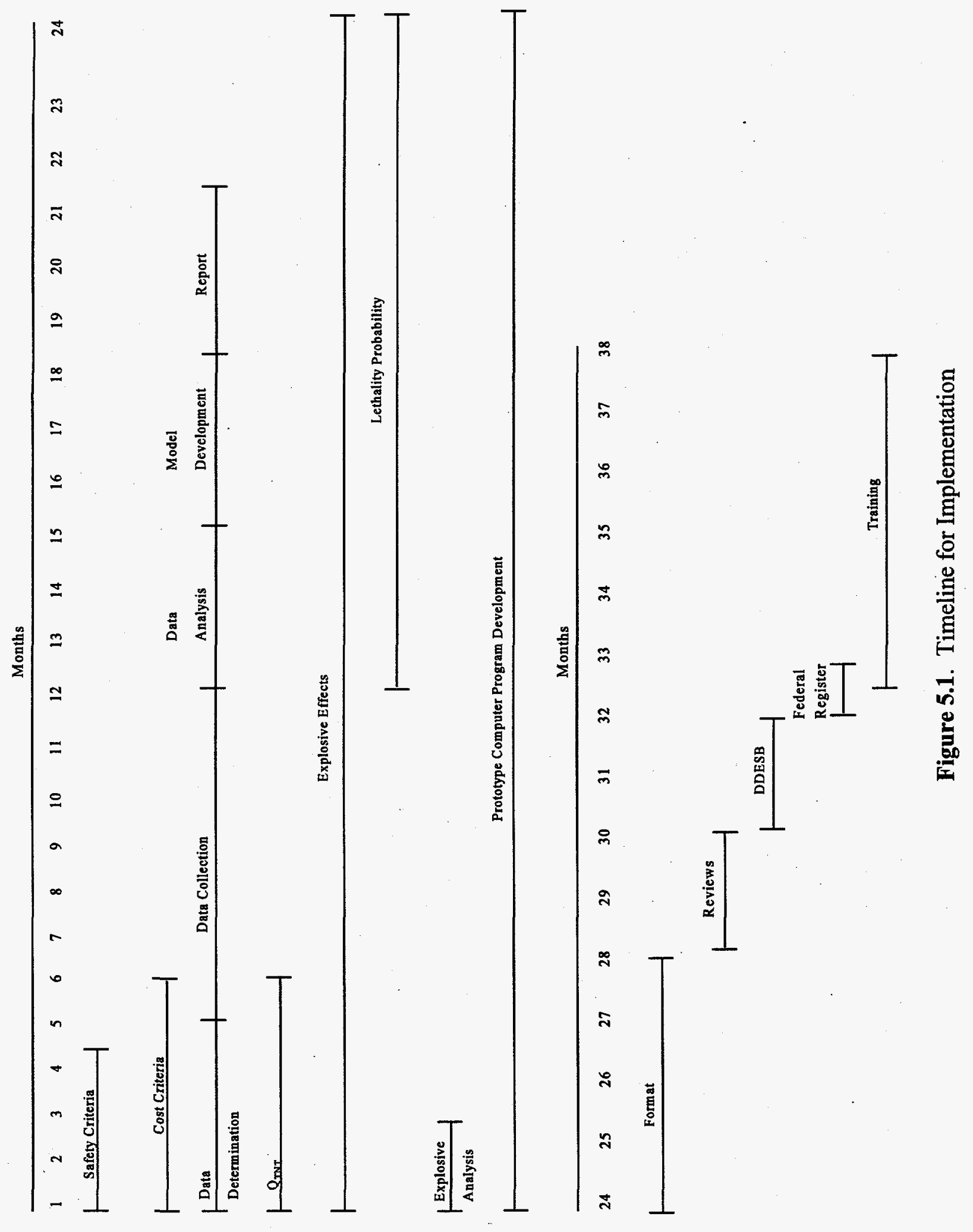




\subsection{Summary}

The risk-based approach to explosives safety should afford the military with significant benefits over those currently afforded by the Q-D approach. Risk can be measured quantitatively not subjectively. Because risk can be estimated, definite individual risk limits can be determined and standardized. Realistic models that address the probabilistic nature of accidental explosions, the actual energy available during an explosion, and the probability that an individual will be exposed would be used.

Military readiness can be improved because it is likely that more munitions can be stored without increasing risk. The number of exemptions and waivers should decrease because scenarios that are now deemed "unsafe" can be examined in terms of actual risk. The application of a risk-based approach should also afford substantial savings in the implementation of safety measures because solutions can be optimized for risk vs cost.

The methodology for performing a risk-based explosives safety assessment is well known and need not be reinvented. However, although considerable data specifically for use in a risk-based methodology have been generated by some foreign government and are likely to be available for use by the United States, these data should be evaluated for applicability to the United States. Any additional data necessary is likely to be already available within safety research. These data of course would have to be collected, analyzed, and formatted for use in a risk-based methodology.

A phased process for implementing a risk-based approach is recommended. The initial usage would focus on resolving noncompliances in the Q-D approach. After a familiarization period, a risk-based approach could be fully implemented. Implementation costs of about five million dollars $(\$ 5,000,000)$ over a period of 38 months are expected. 


\subsection{References}

Bienz, A.F. 1994. "Swiss Safety Concept, Regulations and Organisation in the Field of Military Explosives Safety." Paper presented at the 5th International Symposium on Explosives Technology, October 12-14, 1994. Bienz, Kummer \& Partner Ltd,.Langägertenstrasse 6, CH-8125 Zollikerberg, Switzerland.

Bienz, A.F., and P.O. Kummer. 1992. "How the Safety of the Ammunition and Explosives Storage and Handling is Managed in Switzerland." Paper presented at the 25th Department of Defense Explosives Safety Seminar, Los Angeles, California, August 18-20, 1992. Bienz, Kummer and Partner Ltd., Langägertenstrasse 6, CH-8125 Zollikerberg, Switzerland.

Centers for Disease Control. 1993. Fatal Injuries to Workers in the United States, 1980-1989: A Decade of Surveillance. 93-108, Publications Dissemination, National Institute for Occupational Safety and Health, 4676 Columbia Parkway, Cincinnati, Ohio 45226-1998.

Eglin Air Force Base. March 1993. Explosives Facility Site Planning Pamphlet. Request copy from ASC/YOX \{DSN 872-9113, Ext. 404/Comm. (904) 882-9113, Ext. 404\}, Eglin Air Force Base, Florida 32542-6808.

Swiss Army. 1975. "Technical Regulations for the Storage of Ammunition."

U.S. Department of Defense. 1992. DOD Ammunition and Explosives Safety Standards.

DOD 6055.9-STD. Washington D.C. 


\section{Appendix}

\section{Example Safety Assessments}




\section{Appendix}

\section{Example Safety Assessments}

The following are two examples of a safety assessment based on the risk approach. The first is a simplified example to demonstrate how the individual and perceived collective risks vary as a function of the quantity of stored ammunition. The example also shows the potential importance of taking into account the energy lost in fragmentation and the possibility that not all of the stored ammunition will be involved in the explosion. The second example is a realistic safety explosives situation which is not in compliance with the quantity-distance requirements of DoD 6055.9.

\section{A.1 Example 1: Handling Munitions at an Ammunition Depot}

Figure A.1 gives an overview of the scenario. An ammunition depot, represented by an earth-covered igloo-type magazine, contains a maximum net explosives quantity (NEQ) of 50 tons. The exposed objects in the surrounding area are an access control building where 2 people are present 24 hours a day; a garage/ services center where 5 people are present 8 hours a day, 5 days a week; and a bus stop where 50 people are present for 5 minutes four times each week day. The distances shown in Figure A.1 are not regulation distances, but were chosen to demonstrate the methodology.

Two different situations were analyzed to demonstrate the significance of the casing and participation factors as well as the perceived collective risk. The first is a loading limited to 50 tons NEQ, which is assumed to be 250 gross tons of ammunition. The second is a maximum loading assumed to be 30 tons $\mathrm{Q}_{\mathrm{TNT}}$, assuming the same 250 gross tons of ammunition.

The probability that an explosion would occur in the magazine was assumed based on a linear model for external and internal factors. The hazardous effects were calculated with the computer code RISKAMEXS.

The dominant hazardous effects from the explosion are assumed to be air blast and debris thrown from the crater and buildings and stored items.

Three different situations were distinguished:

1. Only access control personnel are exposed - 24 hours on weekend days and 16 hours on week days (garage/service personnel and bus passengers would not be present on weekends, nor would they be present during the 16 offshift hours of the week day) 


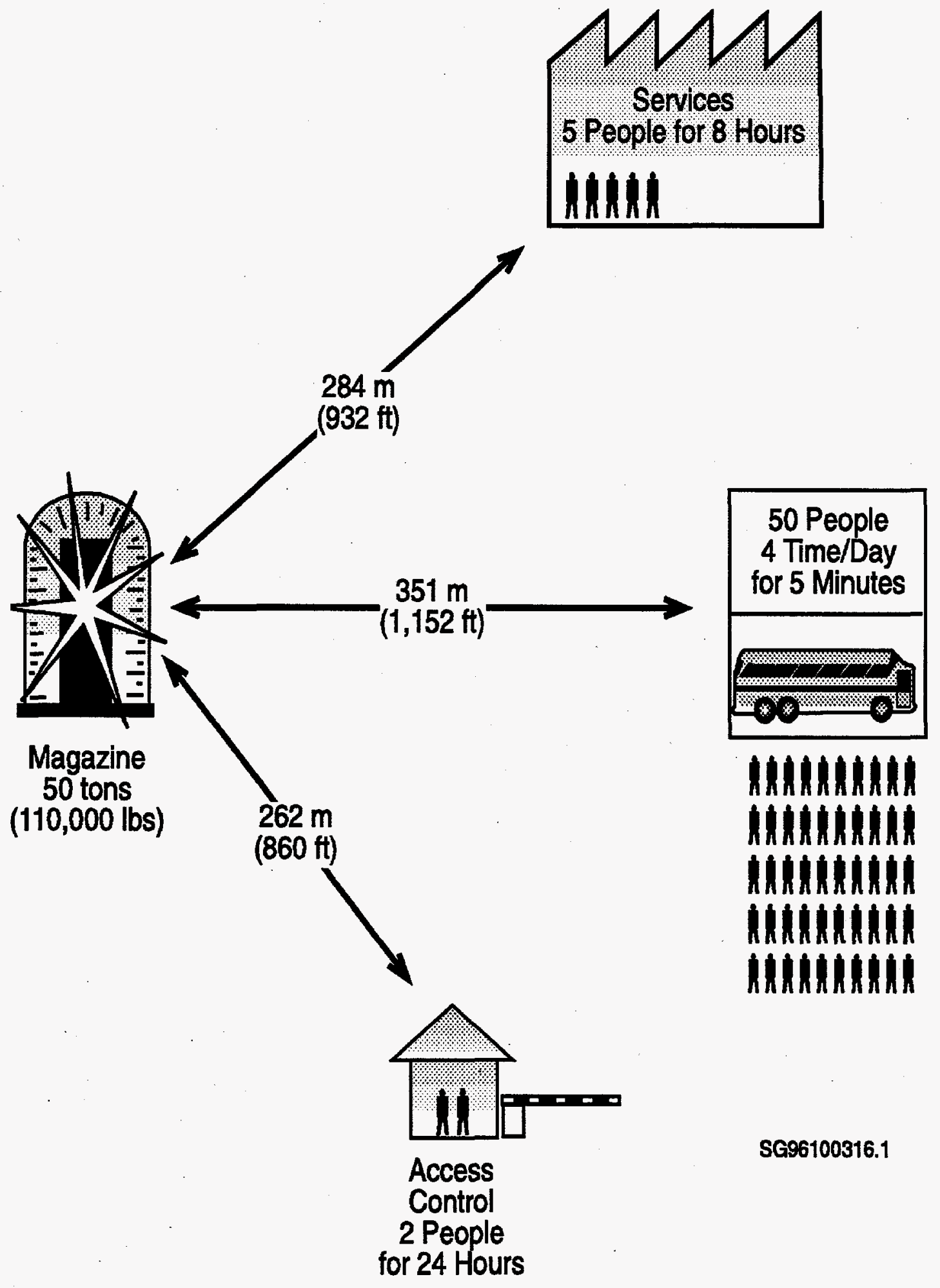

Figure A.1. Layout of Example Scenario - Ammunition Storage 
2. Only access control and garage/services personnel are exposed - 7 hours and 40 minutes per week day (the 8 -hour work day minus the 20 minutes/day that bus passengers are present)

3. Access control personnel, garage/services personnel, and bus passengers are exposed - 20 minutes per week day (four 5-minute bus stops per week day).

The individual risks of the persons exposed at the access control, garage/services, and bus station, as well as the perceived collective risk for all exposed personnel, were calculated using the computer code RISKAMEXS.

Figure A.2 shows the individual risks as a function of the amount of explosives or ammunition, respectively. At 50/250 tons, the total individual risk of personnel at the access control is $7.8 \times 10^{-6} /$ year for a 24-hour day.

If we assume that the access control station is manned for three 8-hour shifts, the individual risk to personnel each shift is $2.33 \times 10^{-6} /$ year. The individual risk of garage/service personnel is $1.3 \times 10^{-6} /$ year, and the individual risk of the bus passengers is $1.3 \times 10^{-7} /$ year. Approximately the same relationships between the individual risks at the three locations can be observed in case of smaller amounts of explosives/ammunition. The bus passengers' lower risk is clearly correlated to their shorter exposure time, although the number of possible lethalities at the bus station is, in fact, distinctly higher than at the other objects.

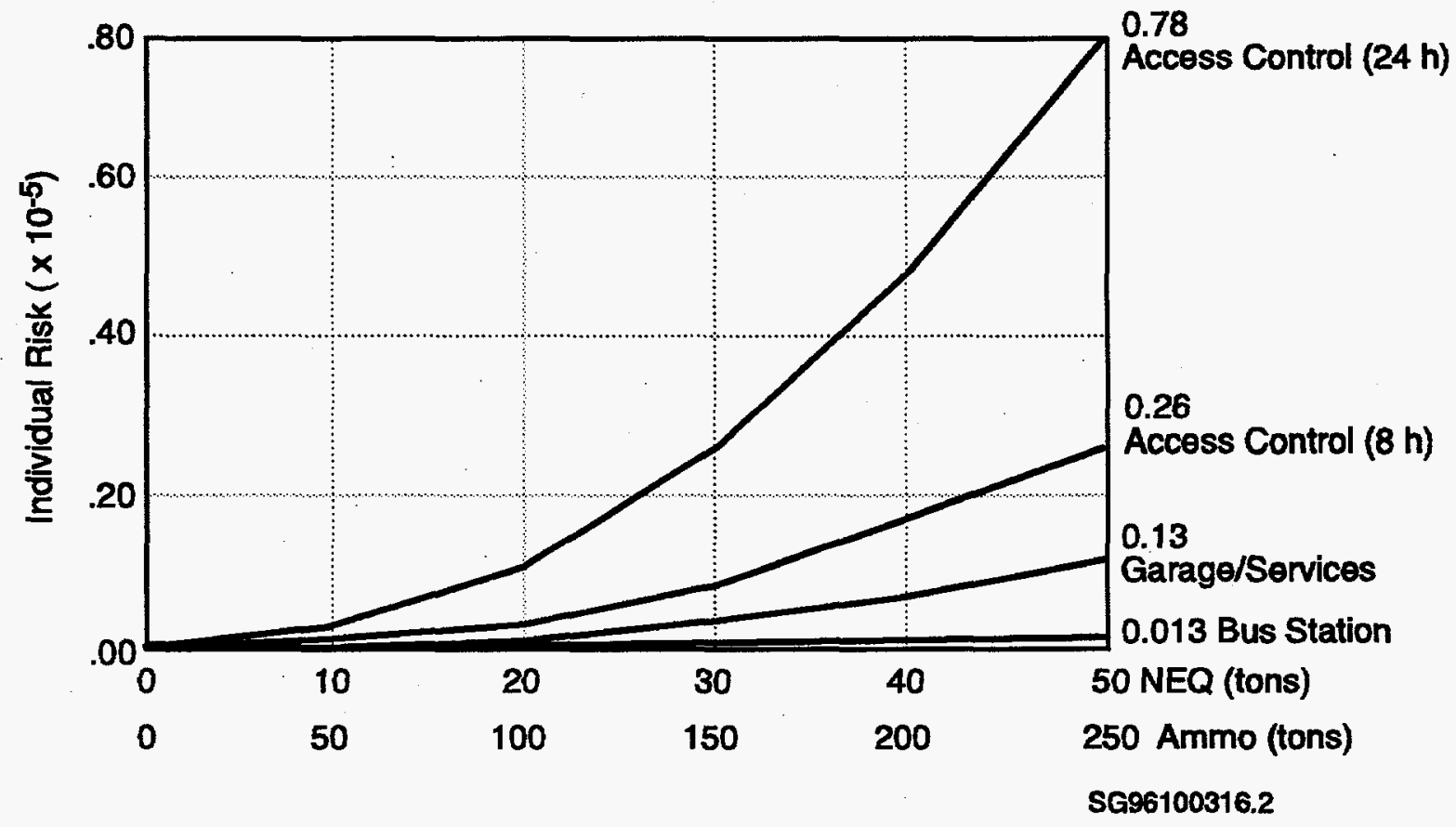

Figure A.2. Individual Risks/Year of the Different Exposed Persons as a Function of the Loading of the Magazine Calculated on NEQ 
Figure A.3 shows the perceived collective risk as a function of the amount of explosives or ammunition, respectively. At 50/250 tons, the total perceived collective risk is $5.25 \times 10^{-5} /$ year. Only $13 \%$ of this total risk is generated among the garage/servicemen and $31 \%$ at the access control, but $56 \%$ of the perceived collective risk is associated with the bus passengers even though the stay times are much shorter. Smaller loadings show about the same relationships.

A comparison of the individual and the collective risks clearly shows that the safety problem at the bus station is not the individual risk of the single passenger, but the collective risk, i.e., high number of people exposed.

The collective risk versus the amount of explosives shown in Figure A.4 contains the curves for NEQ and $\mathrm{Q}_{\mathrm{TNT}}$. This graph demonstrates the distinct benefit of describing the explosives loading as realistically as possible. At the maximum amount of 250 gross tons of ammunition, the risk calculated based on the $\mathrm{Q}_{\mathrm{TNT}}$ approach is only about $40 \%$ of that calculated based on NEQ (see footnote in Section 2). In terms of the loading capacity, the $\mathrm{Q}_{\mathrm{TNT}}$ approach allows (in this particular example) about $50 \%$ more ammunition than the NEQ approach. The same effect can be observed in the case of the individual risks.

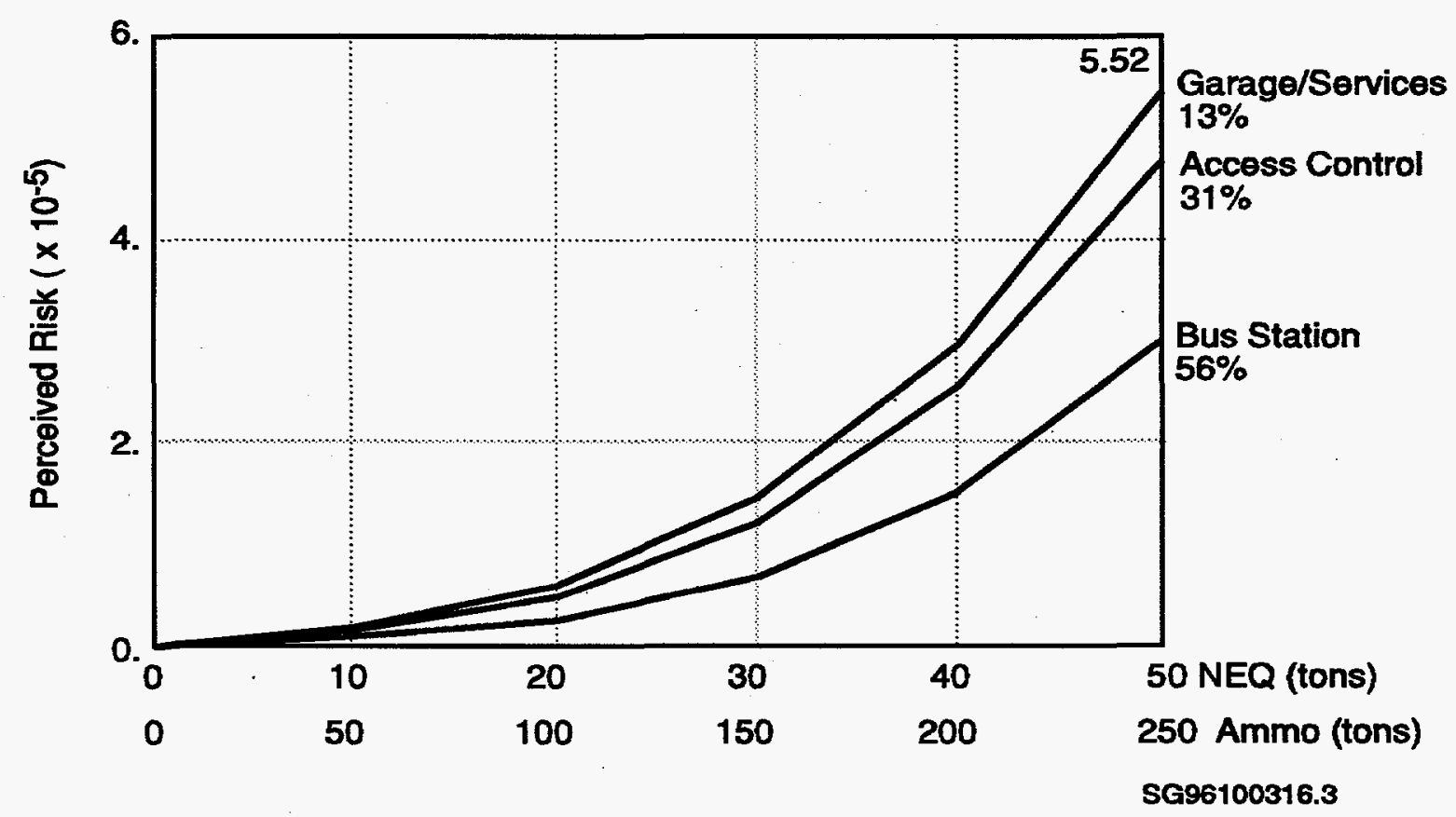

Figure A.3. Perceived Collective Risk/Year of the Magazine as a Function of Its Loading Calculated Based on NEQ 


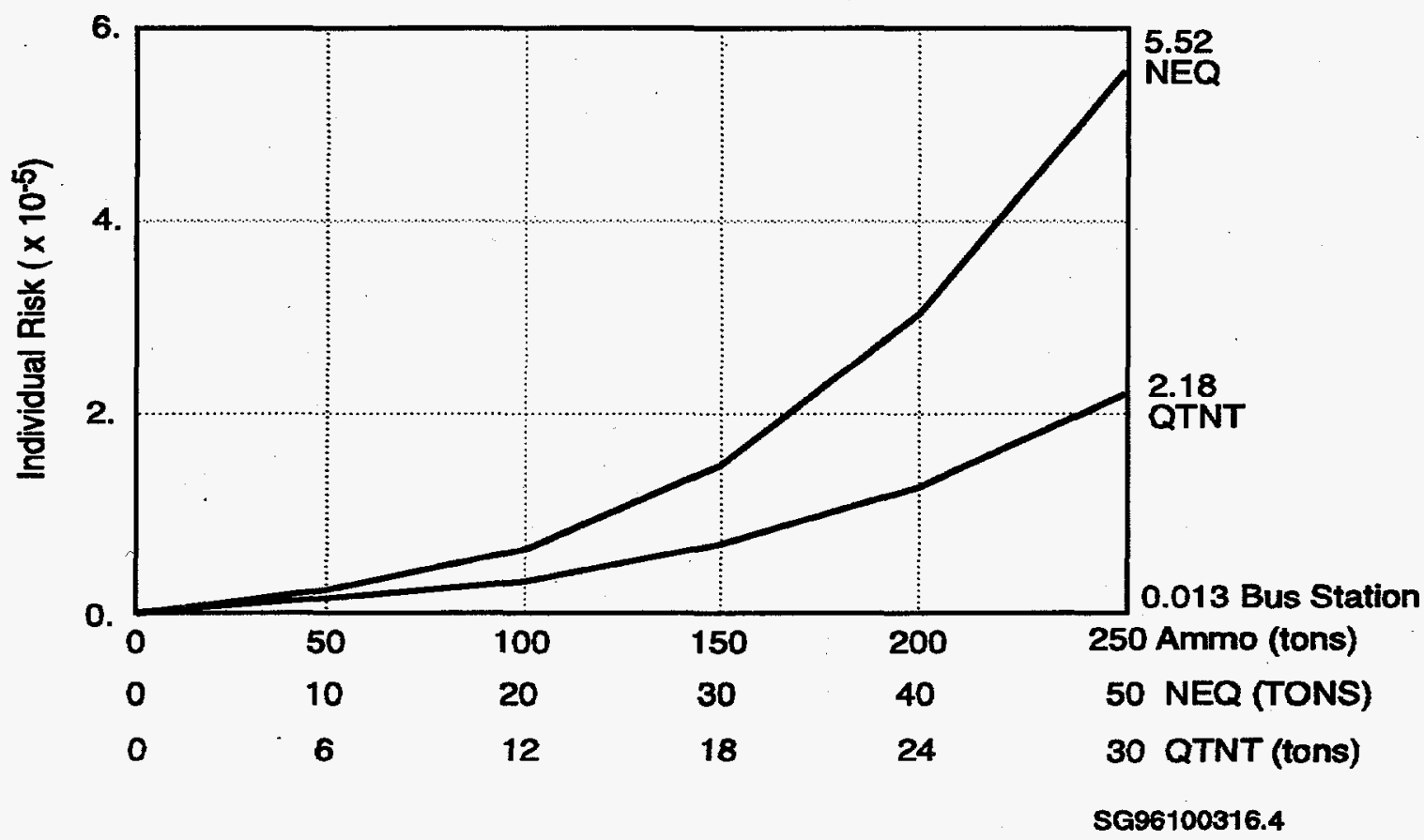

Figure A.4. Comparison of the $\mathrm{Q}_{\mathrm{TNT}}$ and the NEQ Appropriate in the Case of the Perceived Collective Risk as a Function of the Loading to the Magazine

\section{A.2 Example 2: Handling Ammunition on an Air Base}

Figure A.5 gives an overview of the scenario: two maintenance buildings, each with 28 persons and an NEQ of 7.7 tons; and an aircraft shelter with 4 persons and an NEQ of 2.3 tons. As shown, the separation distances are not in compliance with DoD 6055.9 and thus require corrective action or the granting of an exemption or waiver.

In this example, the change in risk between the initial building distances and desired building distances is computed. In addition, the actual geometry was investigated, assuming smaller NEQs in the buildings for two reasons: 1) this examines the idea of solving the problem by reducing the NEQ permitted and 2) it demonstrates the benefits of considering the casing factor and participation factor if these are not considered when performing a Q-D approach.

The loadings assumed for this example for each of the three buildings ( 4 tons in each of the maintenance buildings and 1.5 tons in the aircraft shelter) are considered realistic $\mathrm{Q}_{\mathrm{TNT}}$ values. All individual risks of all persons in all buildings and the collective risks for all donor (PES) buildings and for the overall situation were considered and calculated. 


\section{Explosive Safety Example}

\section{Maintenance Building B}

(above ground, metal frame,

steel plate walls and roofs)

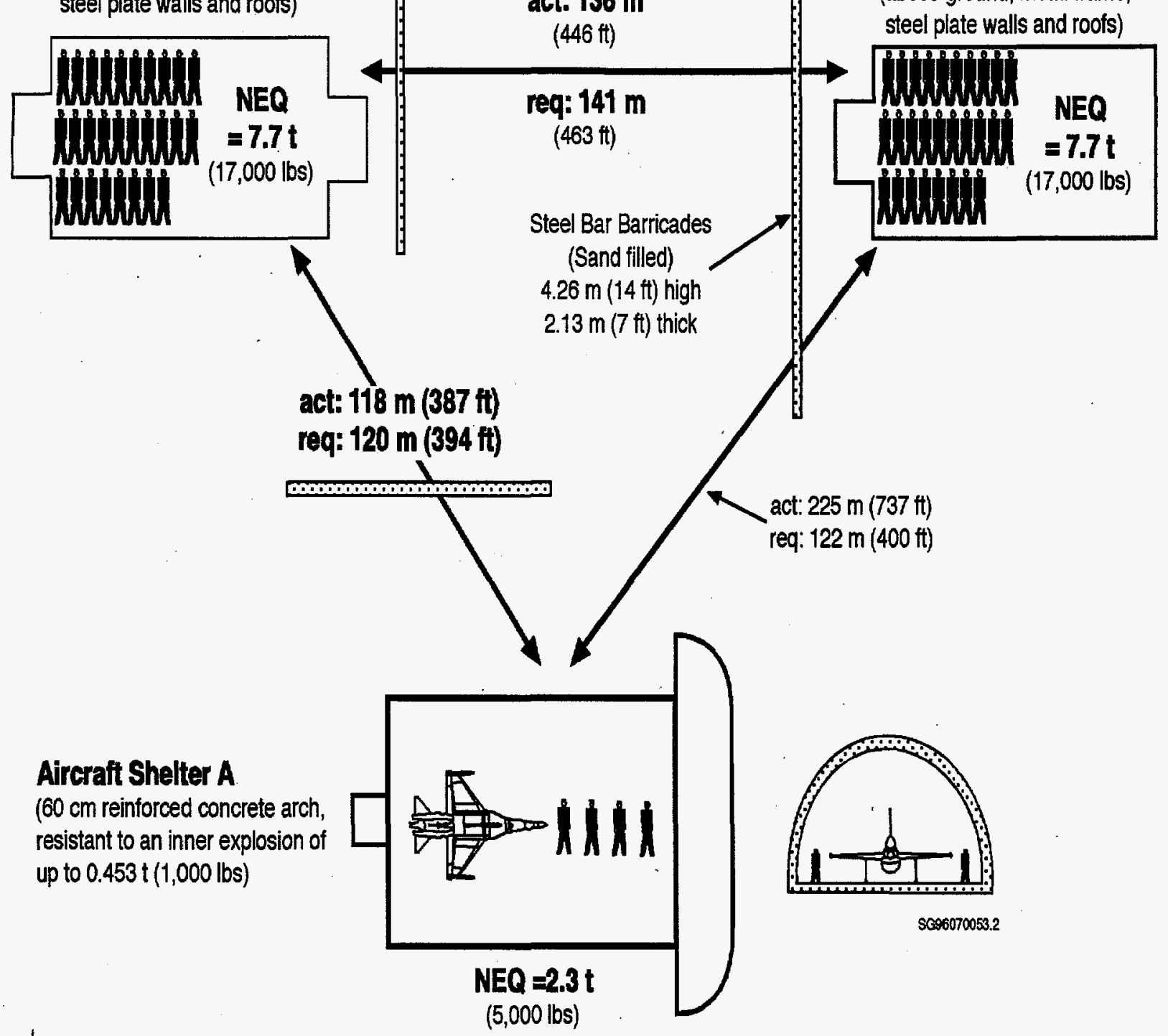

Figure A.5. Layout of Example Scenario -Air Base 
Although the example presented here is that of an actual U.S. military installation, exact details of the explosives and the times when personnel would be in the building were not known, thus assumptions based on experiences at similar facilities were used for demonstration purposes. The activities were assumed to be loading bomb material on aircraft and moving aircraft into and out of the shelters; activity times of 8 hours/day for 200 working days/year were assumed.

In this particular case, it was assumed that an event in the aircraft shelter would always affect the total amount of explosives items; explosives items were assumed to be Class 1 Division 1 (mass detonating) explosives. In the maintenance buildings, a lower probability was assumed for the maximum event because not every event would be expected to cause an explosion of all the items in the building.

The hazardous effects were calculated with the computer code RISKAMEXS. Air blast and debris throw were considered decisive, whereas the fragments were assumed to be blocked by the barricades. The fact that the effects might be intensified by aircraft exploding in the shelter was not considered.

The risk calculation took into account that the total risk to the personnel working in the maintenance buildings is produced not only by the maximum event in their building, but also by the handling of ammunition, which may also cause smaller events that endanger personnel in that building only. Because most of the events in the aircraft shelter were expected to be the maximum ones, the internal risk in the shelter is already included in the calculation of the maximum event.

\section{A.2.1 Risks of the Actual Situation}

The results of the risk calculation are presented in the risk tables. Table A.1 shows the individual risks for the actual NEQ and the actual distances. The cells contain the share of the individual risk of each person in the acceptor buildings (columns) caused by the possible events in the donor (PES) buildings

Table A.1. Individual Risks (fatalities/year) for Maximum NEQs and Actual Distances

\begin{tabular}{|c|c|c|c|}
\hline \multirow[b]{2}{*}{ Donor } & \multicolumn{3}{|c|}{ Acceptor } \\
\hline & $\begin{array}{c}\text { Aircraft } \\
\text { Shelter A }\end{array}$ & $\begin{array}{l}\text { Maintenance } \\
\text { Building B }\end{array}$ & $\begin{array}{l}\text { Maintenance } \\
\text { Building C }\end{array}$ \\
\hline $\begin{array}{l}\text { Aircraft shelter } A \\
Q=2.3 t \\
p=1.00 \times 10^{-5}\end{array}$ & $1.00 \times 10^{-5}$ & $4.62 \times 10^{-7}$ & $1.23 \times 10^{-8}$ \\
\hline $\begin{array}{l}\text { Maintenance Building } B \\
Q=7.7 t \\
p=3.00 \times 10^{-6}\end{array}$ & $8.61 \times 10^{-8}$ & $3.00 \times 10^{-6}$ & $2.77 \times 10^{-7}$ \\
\hline $\begin{array}{l}\text { Maintenance Building C } \\
Q=7.7 t \\
p=3.00 \times 10^{-6}\end{array}$ & $6.51 \times 10^{-9}$ & $2.77 \times 10^{-7}$ & $3.00 \times 10^{-6}$ \\
\hline Internal Risk & & $5.00 \times 10^{-5}$ & $5.00 \times 10^{-5}$ \\
\hline Total & $1.01 \times 10^{-5}$ & $5.37 \times 10^{-5}$ & $5.33 \times 10^{-5}$ \\
\hline
\end{tabular}


(rows). For example, the risk to an individual in the aircraft shelter of an event in the aircraft shelter is $10^{-5} /$ year, while the risk to an individual in building $\mathrm{C}$ is $1.23 \times 10^{-8} /$ year. The total individual risk of a person is the sum of these risk shares. That is, a person in maintenance building $\mathrm{B}$ bears an individual risk of $5.37 \times 10^{-5} /$ year.

Table A.2 shows the perceived collective risks. In the cells, the portion of the perceived collective risk to the acceptor buildings of the NEQs in the donor buildings is shown. The cells in the last column show the total perceived collective risk produced by the respective building. The row "Internal Risk" contains the risk of events smaller than the allowed NEQ, events that have no impact on the neighboring buildings. The total risk of the whole situation is the sum of the risks of all buildings and the internal risks.

Figure A.6 compares the collective risks of all the buildings and shows the composition of the risks. The maintenance buildings generate the same risk, and this risk is more than 100 times greater than that produced by the shelter. The risk is the same because 1) people in these buildings bear a basic risk of their own activities representing more than $50 \%$ and 2) in case of an event of the maximum NEQ within these buildings, 28 persons are affected with $100 \%$ lethality (equal $40 \%$ of the total risk). Thus, only $4 \%$ of the total risk is generated by the surroundings. Also the risk of the aircraft shelter is dominated by the internal risk of the four persons (about 75\%).

Table A.2. Perceived Collective Risks (fatalities/year) for Maximum NEQs and Actual Distances

\begin{tabular}{|l|c|c|c|c|}
\hline \multirow{2}{*}{\multicolumn{1}{|c|}{ Donor }} & \multicolumn{4}{c|}{ Acceptor } \\
\cline { 2 - 5 } & $\begin{array}{c}\text { Aircraft } \\
\text { Shelter A }\end{array}$ & $\begin{array}{c}\text { Maintenance } \\
\text { Building B }\end{array}$ & $\begin{array}{c}\text { Maintenance } \\
\text { Building C }\end{array}$ & All \\
\hline $\begin{array}{l}\text { Aircraft Shelter A } \\
Q=2.3 \mathrm{t} \\
\mathrm{p}=1.00 \times 10^{-5}\end{array}$ & $8.37 \times 10^{-5}$ & $2.71 \times 10^{-5}$ & $7.22 \times 10^{-7}$ & $1.12 \times 10^{-4}$ \\
\hline $\begin{array}{l}\text { Maintenance Building B } \\
\mathrm{Q}=7.7 \mathrm{t} \\
\mathrm{p}=3.00 \times 10^{-6}\end{array}$ & $5.51 \times 10^{-6}$ & $1.34 \times 10^{-3}$ & $1.24 \times 10^{-4}$ & $1.47 \times 10^{-3}$ \\
\hline $\begin{array}{l}\text { Maintenance Building C } \\
\mathrm{Q}=7.7 \mathrm{t} \\
\mathrm{p}=3.00 \times 10^{-6}\end{array}$ & $4.16 \times 10^{-7}$ & $1.24 \times 10^{-4}$ & $1.34 \times 10^{-3}$ & $1.47 \times 10^{-3}$ \\
\hline Internal Risk & & & & \\
\hline
\end{tabular}




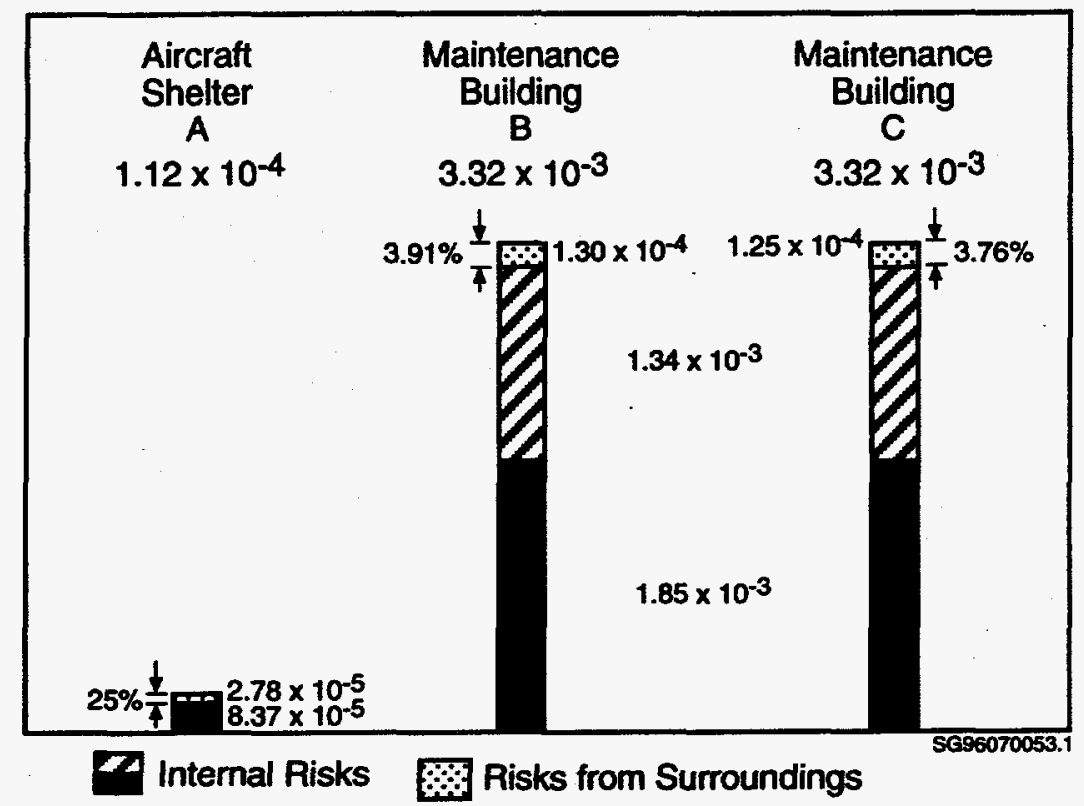

Figure A.6. Comparison and Composition of the Perceived Collective Risks for NEQs and Actual Distances (internal risk includes risk from both the maximum event and a smaller buildingspecific event)

\section{A.2.2 Risk Reduction by Enlarging the Separation DISTANCES}

Tables A.3 and A.4 show the individual and perceived collective risk calculated for the required distances.

In Figure A.7, the individual risk for personnel in Building B for the actual distance is compared with the required distance and the total perceived collective risk for the actual distance is compared with the required distance. Only the perceived collective risk is affected by increasing the distances and only by $-0.6 \%$, which is hardly perceptible. There is no actual safety gain by enlarging the distances; in other words, the actual distance is as safe as the required distance. The individual risk does not change because of the overriding internal risk for Building $B$.

\section{A.2.3 Risk Reduction by Reducing the Maximum Quantities}

Tables A.5 and A.6 show the risks for reduced maximum explosives quantities. As expected, again there is no distinctive safety gain, primarily because the main risks are generated in the donor buildings and not in the surroundings. 
Table A.3. Individual Risks (fatalities/year) for Maximum NEQs and Required Distances

\begin{tabular}{|l|c|c|c|}
\hline \multirow{2}{*}{\multicolumn{1}{|c|}{ Donor }} & \multicolumn{3}{|c|}{ Acceptor } \\
\cline { 2 - 4 } & $\begin{array}{c}\text { Aircraft } \\
\text { Shelter A }\end{array}$ & $\begin{array}{c}\text { Maintenance } \\
\text { Building B }\end{array}$ & $\begin{array}{c}\text { Maintenance } \\
\text { Building C }\end{array}$ \\
\hline $\begin{array}{l}\text { Aircraft Shelter A } \\
\mathrm{Q}=2.3 \mathrm{t} \\
\mathrm{p}=1.00 \times 10^{-5}\end{array}$ & $1.00 \times 10^{-5}$ & $4.18 \times 10^{-7}$ & $1.23 \times 10^{-8}$ \\
\hline $\begin{array}{l}\text { Maintenance Building B } \\
\mathrm{Q}=7.7 \mathrm{t} \\
\mathrm{p}=3.00 \times 10^{-6}\end{array}$ & $7.93 \times 10^{-8}$ & $3.00 \times 10^{-6}$ & $2.44 \times 10^{-7}$ \\
\hline $\begin{array}{l}\text { Maintenance Building C } \\
\mathrm{Q}=7.7 \mathrm{t}\end{array}$ & $6.51 \times 10^{-9}$ & $2.44 \times 10^{-7}$ & $3.00 \times 10^{-6}$ \\
$\mathrm{p}=3.00 \times 10^{-6}$ & & & \\
\hline Internal Risk & & $5.00 \times 10^{-5}$ & $5.00 \times 10^{-5}$ \\
\hline Total & $1.01 \times 10^{-5}$ & $5.37 \times 10^{-5}$ & $5.33 \times 10^{-5}$ \\
\hline
\end{tabular}

Table A.4. Perceived Collective Risks (fatalities/year) for Maximum NEQs and Required Distances

\begin{tabular}{|l|c|c|c|c|}
\hline & \multicolumn{4}{|c|}{ Acceptor } \\
\cline { 2 - 5 } \multicolumn{1}{|c|}{ Donor } & $\begin{array}{c}\text { Aircraft } \\
\text { Shelter A }\end{array}$ & $\begin{array}{c}\text { Maintenance } \\
\text { Building B }\end{array}$ & $\begin{array}{c}\text { Maintenance } \\
\text { Building C }\end{array}$ & All \\
\hline $\begin{array}{l}\text { Aircraft Shelter A } \\
Q=2.3 \mathrm{t} \\
\mathrm{p}=1.00 \times 10^{-5}\end{array}$ & $8.23 \times 10^{-5}$ & $2.41 \times 10^{-5}$ & $7.10 \times 10^{-7}$ & $1.07 \times 10^{-4}$ \\
\hline $\begin{array}{l}\text { Maintenance Building B } \\
\mathrm{Q}=7.7 \mathrm{t} \\
\mathrm{p}=3.00 \times 10^{-6}\end{array}$ & $5.08 \times 10^{-6}$ & $1.34 \times 10^{-3}$ & $1.09 \times 10^{-4}$ & $1.46 \times 10^{-3}$ \\
\hline $\begin{array}{l}\text { Maintenance Building C } \\
\mathrm{Q}=7.7 \mathrm{t}\end{array}$ & $4.16 \times 10^{-7}$ & $1.09 \times 10^{-4}$ & $1.34 \times 10^{-3}$ & $1.45 \times 10^{-3}$ \\
$\mathrm{p}=3.00 \times 10^{-6}$ & & & & \\
\hline Internal Risk & & $1.85 \times 10^{-3}$ & $1.85 \times 10^{-3}$ & $3.69 \times 10^{-3}$ \\
\hline
\end{tabular}



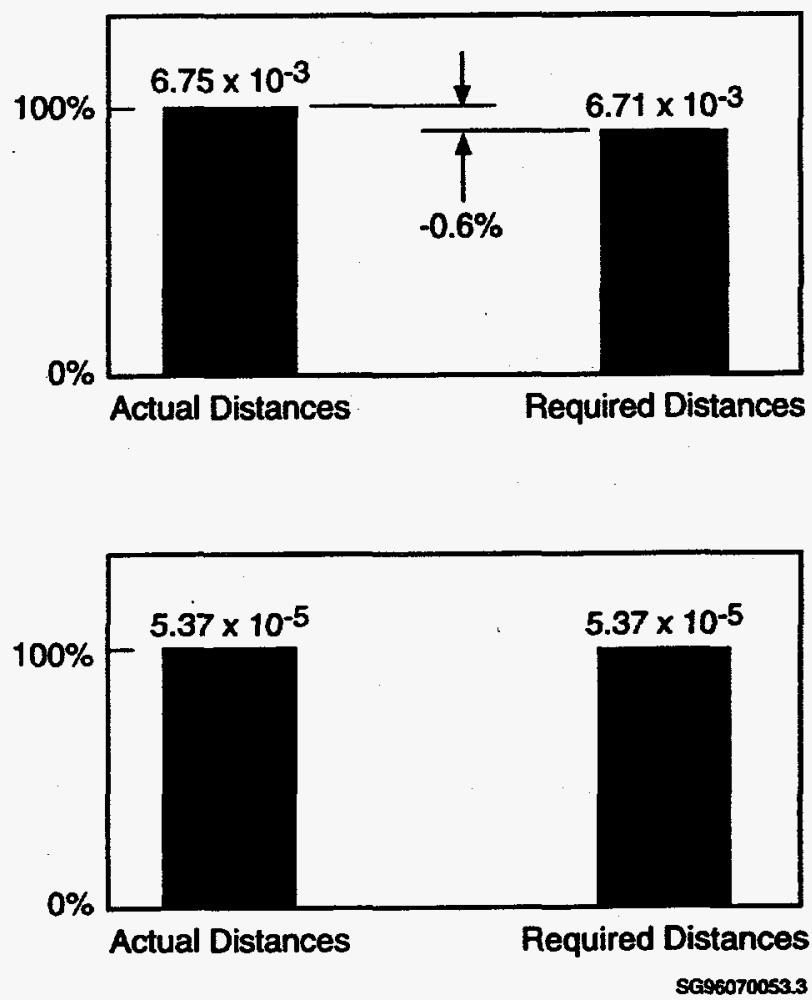

Figure A.7. Comparison of Actual Versus Required Distance. Top graphic shows total perceived collective risks Rp (fatalities/year) for maximum NEQ. Bottom graphic shows the maximum individual risk (fatalities/year) for a person in Building B.

Table A.5. Individual Risks (fatalities/year) for Reduced NEQs (i.e., $\mathrm{Q}_{\mathrm{TNT}}$ ) and Required Distances

\begin{tabular}{|l|c|c|c|}
\hline \multicolumn{1}{|c|}{ Donor } & \multicolumn{3}{|c|}{ Acceptor } \\
\cline { 2 - 4 } & $\begin{array}{c}\text { Aircraft } \\
\text { Shelter A }\end{array}$ & $\begin{array}{c}\text { Maintenance } \\
\text { Building.B }\end{array}$ & $\begin{array}{c}\text { Maintenance } \\
\text { Building C }\end{array}$ \\
\hline $\begin{array}{l}\text { Aircraft Shelter A } \\
Q=1.5 \mathrm{t} \\
\mathrm{p}=1.00 \times 10^{-5}\end{array}$ & $1.00 \times 10^{-5}$ & $2.46 \times 10^{-7}$ & $4.56 \times 10^{-9}$ \\
\hline $\begin{array}{l}\text { Maintenance Building C } \\
\mathrm{Q}=4.0 \mathrm{t} \\
\mathrm{p}=3.00 \times 10^{-6}\end{array}$ & $3.76 \times 10^{-8}$ & $3.00 \times 10^{-6}$ & $9.19 \times 10^{-8}$ \\
\hline $\begin{array}{l}\text { Maintenance Building C } \\
\mathrm{Q}=4.0 \mathrm{t} \\
\mathrm{p}=3.00 \times 10^{-6}\end{array}$ & $2.18 \times 10^{-9}$ & $9.19 \times 10^{-8}$ & $3.00 \times 10^{-6}$ \\
\hline Internal Risk & & & \\
\hline Total & & $5.00 \times 10^{-5}$ & $5.00 \times 10^{-5}$ \\
\hline
\end{tabular}


Table A.6. Perceived Collective Risks (fatalities/year) for Reduced NEQs (i.e., $\mathrm{Q}_{\mathrm{TNT}}$ ) and Required Distances

\begin{tabular}{|c|c|c|c|c|}
\hline \multirow[b]{2}{*}{ Donor } & \multicolumn{4}{|c|}{ Acceptor } \\
\hline & $\begin{array}{l}\text { Aircraft } \\
\text { Shelter A }\end{array}$ & $\begin{array}{c}\text { Maintenance } \\
\text { Building B }\end{array}$ & $\begin{array}{l}\text { Maintenance } \\
\text { Building C }\end{array}$ & All \\
\hline $\begin{array}{l}\text { Aircraft Shelter A } \\
Q=1.5 \mathrm{t} \\
\mathrm{p}=1.00 \times 10^{-5}\end{array}$ & $7.67 \times 10^{-5}$ & $1.32 \times 10^{-5}$ & $2.45 \times 10^{-7}$ & $9.02 \times 10^{-5}$ \\
\hline $\begin{array}{l}\text { Maintenance Building B } \\
Q=4.0 t \\
p=3.00 \times 10^{-6}\end{array}$ & $2.41 \times 10^{-6}$ & $1.34 \times 10^{-3}$ & $4.12 \times 10^{-5}$ & $1.39 \times 10^{-3}$ \\
\hline $\begin{array}{l}\text { Maintenance Building C } \\
Q=4.0 t \\
P=3.00 \times 10^{-6}\end{array}$ & $1.39 \times 10^{-7}$ & $4.12 \times 10^{-5}$ & $1.34 \times 10^{-3}$ & $1.39 \times 10^{-3}$ \\
\hline Internal Risk & & $1.85 \times 10^{-3}$ & $1.85 \times 10^{-3}$ & $3.69 \times 10^{-3}$ \\
\hline & & & Total Risk Rp & $6.56 \times 10^{-3}$ \\
\hline
\end{tabular}

For the same reason, it could be argued that the $\mathrm{Q}_{\mathrm{TNT}}$ concept does not produce a relevant safety effect. Actually, the $\mathrm{Q}_{\mathrm{TNT}}$ concept has its roots in the ammunition storage where the main risks are those in the surroundings of the magazines. Thus, one view might be that the concept of taking the casing and participation factors $\left(\mathrm{Q}_{\mathrm{TNT}}\right)$ into consideration does not produce a relevant safety effect. This example masks the benefit because of the high internal risk. The benefit of the $\mathrm{Q}_{\mathrm{TNT}}$ is realized when the only risk is from the surroundings. In Figure A.8, the risks from the surroundings generated by the actual NEQs are compared with those of the $\mathrm{Q}_{\mathrm{TNT}}$. Because the range of the hazardous effects is smaller in the surroundings, both the collective and the individual risks are reduced considerably, in this particular case more than $50 \%$.

\section{A.2.4 Risk Appraisal}

The Swiss safety criteria are formulated for three risk groups: the directly involved, the indirectly involved, and third parties. In this particular case, only directly involved (personnel in the donor building) and indirectly involved (personnel in the acceptor buildings) are affected.

For the individual risks the upper limiting values are

- $5.10^{-5} /$ year for the indirectly involved

- $10^{-4} /$ year for directly involved (including both direct and indirect values). 

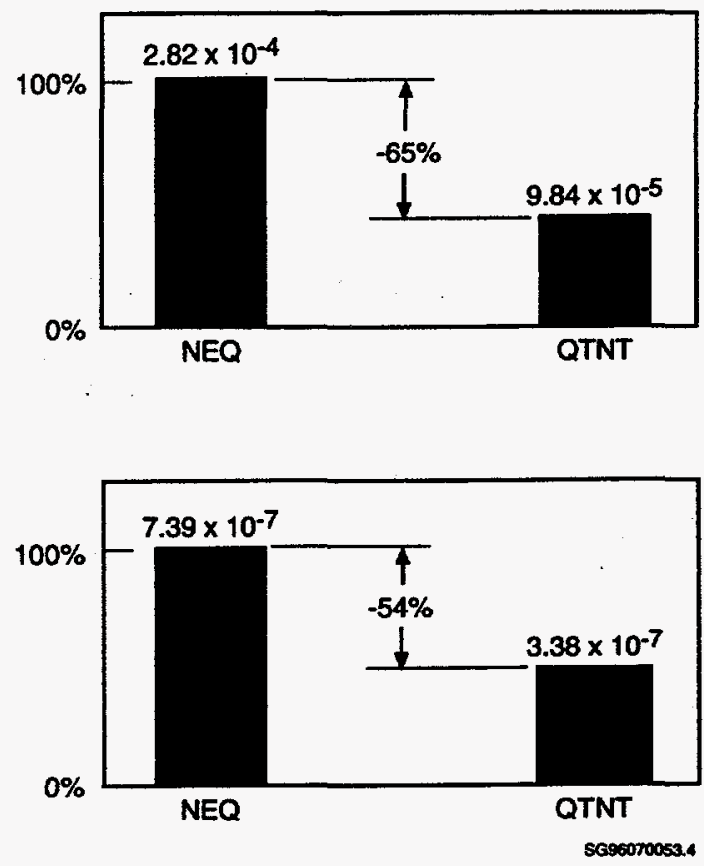

Figure A.8. Comparison of Actual and Reduced $\left(\mathrm{Q}_{\mathrm{TNT}}\right)$ Explosives Quantities on the Risks Generated in the Surroundings. Top graphic shows total perceived collective risks Rp (fatalities/year) in surroundings and actual situation. Bottom graphic shows individual risk (fatalities/year) in surroundings, e.g. Building B, actual situation.

The perceived collective risks have to be limited by applying the cost criterion for risk-reducing measures. The marginal costs are

- 8 million $\$ /$ life-saved for indirectly involved

- 4 million $\$ /$ life-saved for directly involved.

As Figure A.9 shows, the individual risk of all personnel complies with the safety criteria. According to Swiss criteria for individual risk, the situation with NEQs and actual distances can be considered safe. 

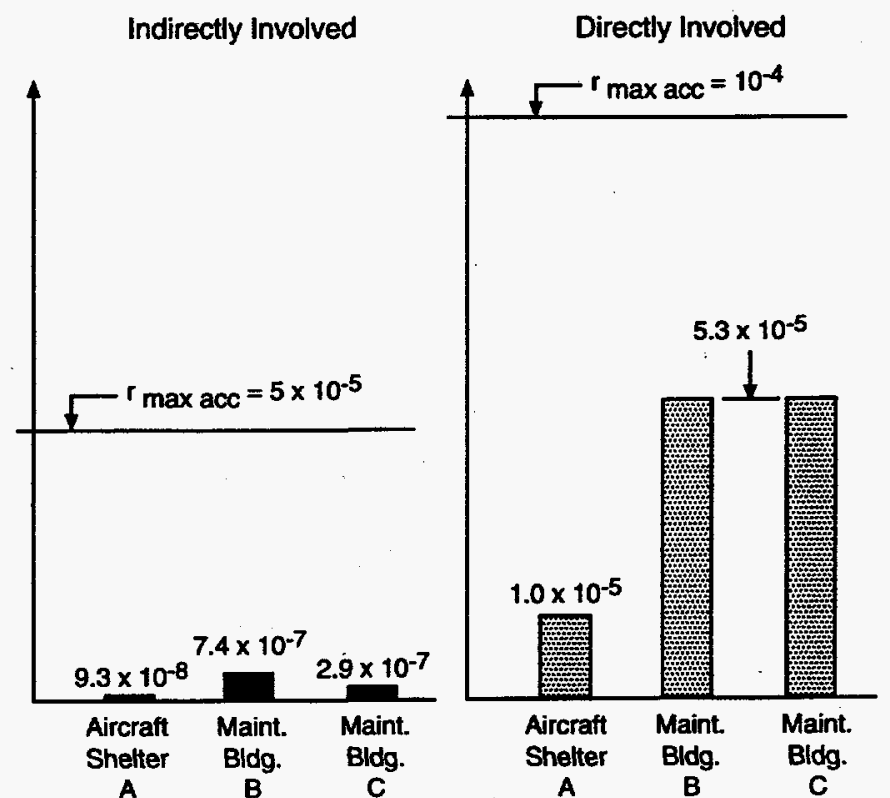

Figure A.9. Appraisal of the Individual Risk Versus the Swiss Safety Criteria

The perceived collective risk has to be appraised in a risk/cost-diagram. Figure A.10 shows such a diagram with the total risk-group-adjusted ${ }^{(a)}$ perceived risk and the straight line of marginal cost entered.

Additional safety measures, their costs, and the amount of risk reduction have to be identified and added to the risk/cost diagram. If all values are above the marginal cost line (Case A), the situation is declared safe. If values appear below the line, i.e., if additional measures that have a better riskreduction/cost effect than the marginal cost can actually be taken (Case $\mathrm{B}$ ), the funds necessary to reduce the risk by the determined amount (in this case, about $\$ 5000 /$ year) have to be spent. Thus, the situation is declared unsafe until these corrective measures are taken. If no more sufficiently cost-effective measures apart from Case B can be found, Case B is declared safe with an accepted residual collective risk of $3.0 \mathrm{x}$ $10^{-3}$ in this particular example.

(a) Because it is only possible to enter one tangent of marginal cost, the collective risks belonging to different risk groups (with different marginal cost) have to be adjusted against one group. In this particular case, the tangent of the directly involved was chosen. Thus, the risks generated in the neighboring buildings, belonging to the group of indirectly involved, had to be multiplied by the factor given by the different marginal cost $(8 \mathrm{million} / 4 \mathrm{million}=2)$. This calculation results in a total group adjusted collective risk $\left(7.03 \times 10^{-3}\right)$ that is higher than the total risk in the matrix of Table A.2 $\left(6.75 \times 10^{-3}\right)$. 


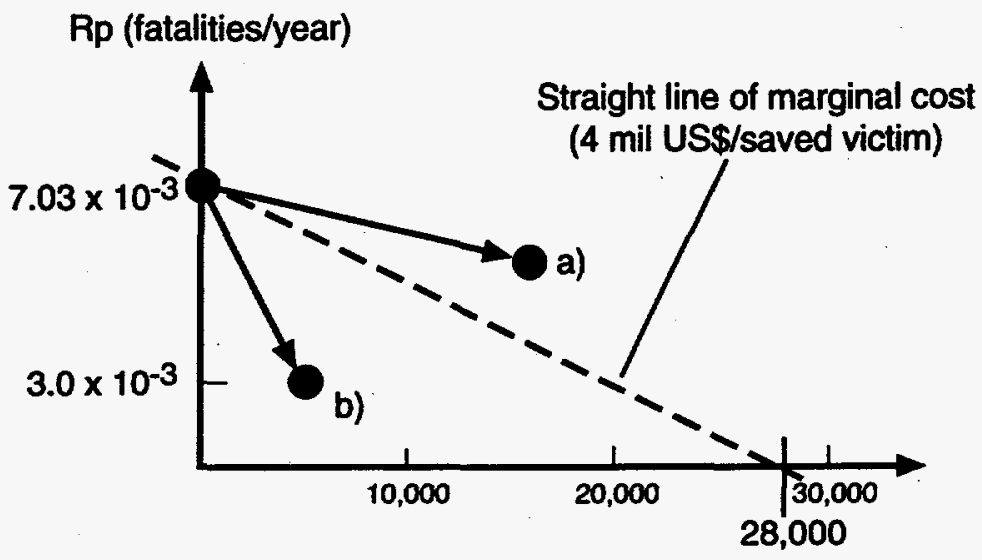

Cost for Safety Measures (US\$/year)

SG96070053.6

Figure A.10. Appraisal of the Collective Risk Versus the Swiss Safety Criteria 